\title{
Effects of 5-FU and anti-EGFR antibody in combination with ASA on the spherical culture system of HCT116 and HT29 colorectal cancer cell lines
}

\author{
AGATA OLEJNICZAK-KĘDER, MAGDALENA SZARYŃSKA, AGATA WROŃSKA, \\ KAMILA SIEDLECKA-KROPLEWSKA and ZBIGNIEW KMIEĆ \\ Department of Histology, Medical University of Gdansk, 80-211 Gdansk, Poland
}

Received January 29, 2019; Accepted May 6, 2019

DOI: $10.3892 /$ ijo.2019.4809

\begin{abstract}
The aim of this study was to examine the effects of 5-fluorouracil (5-FU), anti-epidermal growth factor receptor (EGFR) antibody and aspirin (ASA) on the characteristics of two CRC cell lines, HCT116 and HT29, maintained in a spherical culture system. We observed that the morphology of both the HCT116 and HT29 cell-derived spheres was significantly impaired and the size of the colonospheres was markedly reduced following treatment with the aforementioned three drugs. In contrast to adherent cultures, the spherical cultures were more resistant to the tested drugs, as was reflected by their capacity to re-create the colonospheres when sustained in serum-free medium. Flow cytometric analysis of the drug-treated HCT116 cell-derived spheres revealed changes in the fraction of cells expressing markers of cancer stem cells (CSCs), whereas the CSC phenotype of HT29 cell-derived colonospheres was affected to a lesser extent. All reagents enhanced the percentage of non-viable cells in the colonospheres despite the diminished fraction of active caspase-3-positive cells following treatment of the HT29 cell-derived spheres with anti-EGFR antibody. Increased autophagy, assessed by acridine orange staining, was noted following the incubation of the HT29-colonospheres with ASA and 5-FU in comparison to the control. Notably, the percentage of cyclooxygenase (COX)-2-positive cells was not affected by ASA, although its activity was markedly elevated in the colonospheres incubated with anti-EGFR antibody. On the
\end{abstract}

Correspondence to: Mrs. Agata Olejniczak Kęder, Department of Histology, Medical University of Gdansk, 1 Dębinki Street, 80-211 Gdansk, Poland

E-mail: agata.olejniczak-keder@gumed.edu.pl

Abbreviations: 5-FU, 5-fluorouracil; ASA, aspirin; CRC, colorectal cancer; CSC, cancer stem cell

Key words: colorectal cancer cell lines, spherical cultures, cancer stem like cells, 5-fluorouracil, anti-epidermal growth factor receptor antibody, aspirin whole, the findings of this study indicate that all the tested drugs were involved in different cellular processes, which suggests that they should be considered for the combined therapeutic treatment of CRC, particularly for targeting the population of CSC-like cells. Thus, cancer cell-derived spheres may be used as a preferable model for in vitro anticancer drug testing.

\section{Introduction}

Colorectal cancer (CRC) is the third most commonly diagnosed malignancy and the fourth leading cause of cancer-related mortality worldwide (1). It is expected that the number of patients with CRC will increase by $60 \%$, to exceed 2.2 million by the year 2030 (1). Despite significant progress being made over the past decades, a number of events related to the pathogenesis, metastasis, progression and relapse of CRC remain unclear. During the past 10 years, seminal studies have provided evidence of the existence of cancer stem cell-like cells (CSC-like cells) in $\mathrm{CRC}$. These cells represent a specific tumor cellular fraction with the ability to self-renew, an unregulated proliferation resulting in abnormal growth, slow-cycling, and differentiation into a non-tumorigenic cell progeny $(2,3)$. CSC-like cells seem to play a crucial role in the resistance to conventional chemotherapy that is directed mainly against rapidly replicating cells. Moreover, it has been suggested that chemotherapy and/or radiotherapy may contribute to the formation of a CSC-like population (4). CSC-like cells also participate in the mechanisms of metastasis since epithelial-mesenchymal transition (EMT) and cells with a CSC-like phenotype share similar molecular pathways $(5,6)$. Hence, the isolation and advanced characterization of CSC-like cells is claimed as a pre-requisite of effective CRC treatment.

Marked investments in the cancer research field have not yet improved new cancer drug approval rates, which are estimated at $<5 \%$ and are markedly lower than those in other therapeutic areas, e.g., 20\% for cardiovascular diseases (7). Although a number of factors contribute to such a poor result of anticancer drug development, one of the most relevant involves inadequate models for the testing of agents. The commonly used preclinical models fail to recapitulate the complexity and heterogeneity of human cancers and the hampered drug penetration into different areas of the tumor bulk, which occurs in the natural microenvironment $(8,9)$. Monolayer 
cell cultures are unable to mimic the natural elements of the tumor spatial organization. Hence, in recent years, spherical models of cancer cell cultures have gained popularity, as they more adequately represent tumor growth and in vivo development $(2,3,8,10,11)$. Therefore, a crucial process for the effective testing of anticancer drugs is the development of novel in vitro cell culture systems that can better reproduce such traits of in vivo tumors as varied expression of genes, access to nutrients, oxygen, growth factors or waste metabolites delivery systems (8). Notably, spherical cultures were presented as a population enriched in cells possessing CSC-like traits (12). This statement was based on the unusual features of CSC-like cells which do not require connections to extracellular matrix molecules or other cells, whereas non-CSC-like cells required such junctions with the environment for survival. By contrast, non-CSC-like cells undergo anoikis when they are not anchored, unless they are protected by cytokines or exosomes released by CSC-like cells $(13,14)$, but of note is the fact that spheres also contain more differentiated tumor cells. A number of different approaches have been proposed to detect and isolate CSC-like cells from the overall tumor cell population, such as cell sorting, functional tests based on their colony-formation ability or resistance to chemo- or radiotherapy, molecular analyses using PCR techniques and image-based methods (15). As CSC-like cells can be characterized by the expression of some cell-surface antigens and soluble proteins, cell sorting is one of the most commonly used techniques for the isolation of CSC-like cells. However, CSC-like cells represent a diversified population which can reside in multiple, alternative phenotypic states within a tumor, accounting for intratumoral cell heterogeneity $(16,17)$. Although cell sorting can enrich the cancer cell population with cells possessing tumor-initiating capacity, the expression of CSC-markers is variable, not only among patient samples, but also between established cancer cell lines $(2,3,10,18,19)$. Independently of some discrepancies in the estimations of the number of CSC-like cells within spherical cell culture systems, it can be claimed that spherical models present a useful tool for testing the effectiveness of anticancer agents.

Despite the continuous therapeutic progress, cancer recurrence and therapeutic resistance still occur in the majority of patients. Conventional treatment with CRC-targeting chemotherapeutic regimens principally include different combinations of 5-fluorouracil (5-FU), oxaliplatin, leucovorin or irinotecan (20). However, patients evolve resistance to these therapeutics, which necessitates attempts to improve the efficacy of treatment through the combination of drugs. Studies published over the past decade have suggested that 5-acetylsalicylic acid (or aspirin; ASA) may be effective in primary cancer prevention and in reducing the risk of adenomas and CRC; e.g., the use of ASA was associated with a $28 \%$ reduction in the risk of death from CRC and a $12 \%$ reduction in the risk of death from any type of cancer (21). ASA has been also investigated in other types of cancer, including esophageal, breast, prostate and lung cancer (22). The exact mechanisms of action of ASA as regards anticancer prevention/treatment have not yet been fully explained. ASA irreversibly, but not selectively, inactivates both cyclooxygenase (COX)-1 and COX-2 (22). Moreover, ASA may be involved in the inhibition of the mammalian target of rapamycin (mTOR) signaling pathway (23) and in the induction of AMP-activated protein kinase (23), affecting the phosphoinositide 3-kinase (PI3K) pathway (24) or its crosstalk with COX-2 (24). ASA and its prodrugs may also affect CSC-like cells through the disruption of nuclear factor (NF)- $\mathrm{B}$ activity $(25,26)$ or the inhibition of prostaglandin-endoperoxide synthase 2 (PTGS2) and the activation of peroxisome proliferator-activated receptor $\gamma$ (PPARG) (27). Targeting epidermal growth factor receptor (EGFR) by monoclonal antibodies was previously presented as an effective therapy in some patients with CRC $(20,28)$. These anticancer drugs may affect major downstream pathways activated by EGFR, such as the RAS/RAF/mitogen-activated protein kinase (MAPK), $\mathrm{PI} 3 \mathrm{~K} /$ phosphatase and tensin homologue (PTEN)/AKT and JAK/signal transducer and activator of transcription (STAT) pathways, and may thus regulate/inhibit cancer cell growth and proliferation $(28,29)$.

The aim of this study was to assess the effects of 5-FU, anti-EGFR antibody and ASA on the behavior and survival of colonospheres derived from CRC cell lines cultured in a serum-free medium. We performed multiple analyses to determine the effects of the tested therapeutic agents, alone or in combination, on the cancer cells with particular focus on the CSC-like cells present within the spherical cultures. In particular, we paid attention to the CSC-suppressing activity of the agents included in this study.

\section{Materials and methods}

Cell lines and cell culture. The HT29 human adenocarcinoma colorectal cell line and HCT116 human colorectal carcionoma cell line were originally purchased from the American Type Culture Collection (ATCC). The cells were cultured at $37^{\circ} \mathrm{C}$ under a humidified atmosphere of $5 \% \mathrm{CO}_{2}$ in medium recommended by ATCC, i.e., McCoy's medium supplemented with $10 \%$ fetal bovine serum (FBS), $1 \%$ penicillin-streptomycin and $2 \mathrm{mM}$ L-glutamine. All experimental chemicals were purchased from Sigma-Aldrich.

Expansion of CRC lines in the spherical form and incubation with the tested drugs. The original adherently cultured cells were cultivated in the medium recommended by the manufacturer, trypsinized, washed twice in PBS and maintained in a serum-free stem cell medium (referred to as SCM) containing DMEM-F12 supplemented with ITS Liquid Media Complement, $5 \mathrm{mM}$ HEPES, $4 \mathrm{mg} / \mathrm{ml}$ bovine serum albumin (BSA), $2 \mathrm{nM}$ L-glutamine, $20 \mathrm{ng} / \mathrm{ml}$ epidermal growth factor (EGF), $20 \mathrm{ng} / \mathrm{ml}$ basic fibroblast growth factor (bFGF) and antibiotic antimycotic solution. For passaging, the spheroid cultures were collected into a tube, centrifuged (400 x g; $10 \mathrm{~min} ; 4^{\circ} \mathrm{C}$ ) and resuspended in fresh SCM following rigorous pipetting to dissociate the the spheres into cell suspension. All experimental chemicals were purchased from Sigma-Aldrich, apart from the growth factors, which were purchased from R\&D Systems.

A total of $5 \times 10^{6}$ cells were seeded in 24-well ultra-low attachment plates and maintained in SCM. After 4 passages, the newly formed spheres were treated with $50 \mu \mathrm{M} 5-\mathrm{FU}$, $1.5 \mathrm{mM}$ ASA (both from Sigma-Aldrich), $20 \mu \mathrm{g} / \mathrm{ml}$ anti-EGFR antibody (Santa Cruz Biotechnology) or their combinations dissolved in a freshly prepared culture medium. 5-FU 
and anti-EGFR antibody solutions were prepared in DMEM/F12 medium, whereas ASA was dissolved in dimethyl sulfoxide (DMSO) (Sigma-Aldrich). In all the experiments, the DMSO concentration was never higher than $1 \%$ (v/v) and did not affect cell growth. All solutions were prepared immediately prior use. The control cells were maintained in SCM. Changes in the morphology and size of the spheres were determined after $72 \mathrm{~h}$ of incubation at $37^{\circ} \mathrm{C}$ (under a humidified atmosphere of $5 \% \mathrm{CO}_{2}$ ) under an inverted microscope Olympus-CKX53 coupled with Olympus SC50 digital camera (Olympus).

Sphere formation following pre-treatment of adherent cells with the tested drugs. The assay was carried out with an aim to determine the ability of CRC cell lines to form colonospheres following 72-h-long incubation (at $37^{\circ} \mathrm{C}$ ) of the cells cultured in adherent form with the tested drugs. A total of $5 \times 10^{6}$ of parental adherent cells were cultured in standard 24-well plates in complete McCoy's medium (Sigma-Aldrich) and incubated at $37^{\circ} \mathrm{C}$ for $24 \mathrm{~h}$ to induce cell adherence. The medium was then removed and replaced with complete McCoy's medium supplemented with $50 \mu \mathrm{M}$ 5-FU, $1.5 \mathrm{mM}$ ASA, or $20 \mu \mathrm{g} / \mathrm{ml}$ anti-EGFR, alone or in combination for $72 \mathrm{~h}$. Subsequently, the cells were washed with PBS (Sigma-Aldrich) and suspended in the bovine serum-free SCM in 24-well ultra-low attachment plates for 7 days. The medium was replaced every 3 days. The ability of the cells to form colonospheres was assessed after that time was documented by a series of images obtained using an inverted microscope (Olympus).

Secondary sphere formation. A total of $5 \times 10^{6}$ adherent cells were seeded in 24-well ultra-low attachment plates and maintained in DMEM/F12 (Sigma-Aldrich) with all the required supplements. After 4 passages, the spheres were treated with $50 \mu \mathrm{M} 5$-FU, $1.5 \mathrm{mM}$ ASA, $20 \mu \mathrm{g} / \mathrm{ml}$ anti-EGFR antibody or their combination for $72 \mathrm{~h}$. The cells were then collected, washed in PBS (Sigma-Aldrich) and resuspended in fresh supplemented DMEM/F12 medium. The cells were then seeded in 24-well ultra-low attachment plate for 7 days. Their ability to form colonospheres was assessed after that time and documented by a series of images obtained using an inverted microscope (Olympus).

Phenotypic analysis of cell suspensions obtained from colonospheres. Colonospheres were washed with rigorous pipetting in PBS (Sigma-Aldrich) for $5 \mathrm{~min}$ to obtain a suspension of individual cells. Subsequently, $1 \times 10^{5}$ cells were suspended in $100 \mu \mathrm{l}$ and stained with $10 \mu \mathrm{l}$ of the following monoclonal antibodies: anti-CD29-APC (clone MAR4, IgG1, $\kappa$ ) (559883), anti-CD44-FITC (clone, G44-26, IgG2b, к) (555478), anti-FasL-biotin (clone NOK-1, IgG1) (556374) coupled with streptavidin-APC (554067), anti-CD95-PE (555674) (all from BD Biosciences) and anti-CD133/2-PE (clone 293C3, IgG2b, $\kappa$ ) (130-112-195; Miltenyi Biotec). Following incubation for $30 \mathrm{~min}$ in the dark at room temperature, the samples were resuspended in PBS with EDTA (Sigma-Aldrich) (to avoid cell clustering) for further analysis. Flow cytometric analyses were performed using a FACSCalibur flow cytometer (BD Biosciences) and BD CellQuest Pro Software. The acquisition gates were restricted to cell gates based on morphological characteristics (FSC-Forward SCatter vs. SSC-Side SCatter), and at least
30,000 cells were acquired and analyzed. The results are expressed as a percentage of the studied cell population. Data were further analyzed with BD CellQuest Pro software (BD Biosciences).

Cell death assay. The 7-aminoactinomycin D (7-AAD) dye (BD Biosciences), a DNA-binding compound, was used for the cytometric measurement of the fraction of dead cells. Following the addition of $10 \mu \mathrm{l}$ of Via-Probe reagent, $1 \times 10^{5}$ cells were incubated for $30 \mathrm{~min}$ at room temperature, washed and re-suspended in PBS with EDTA (Sigma-Aldrich) prior to cytometric analysis. The acquisition gates were restricted to cell gates based on morphological characteristics (FSC vs. SSC), and at least 30,000 cells were acquired and analyzed. The results are expressed as a percentage of the studied cell population.

Analysis of apoptotic and necrotic cells. The Annexin-V-FITC Apoptosis Detection kit I was used to measure the translocation of phosphatidylserine within the membranes of apoptotic cells according to the manufacturer's instructions (BD Biosciences). A total of $1 \times 10^{6}$ cells were suspended in $1 \mathrm{ml}$ of binding buffer. Subsequently, $5 \mu \mathrm{l}$ of Annexin-V (An-V)-FITC and $5 \mu \mathrm{l}$ of propidium iodide (PI) were added, gently pipetted and the cells were then incubated for $15 \mathrm{~min}$ at room temperature in the dark. After that time, $400 \mu \mathrm{l}$ of binding buffer were added and flow cytometric analysis was performed within $1 \mathrm{~h}$. All experimental chemicals were purchased from BD Biosciences. The acquisition gates were restricted to cell gates based on morphological characteristics (FSC vs. SSC), and at least 30,000 cells were acquired and analyzed. The results are expressed as a percentage of the studied cell population.

Caspase-3 activation assay. Caspase-3, synthesized as an inactive pro-enzyme, is a key protease that is activated during apoptosis. The percentage of cells with active caspase-3 was measured cytometrically by applying monoclonal anti-active-caspase- 3 antibody. A total of $1 \times 10^{6}$ cells were suspended in the Fixation/Permeabilization solution for $20 \mathrm{~min}$ at $4^{\circ} \mathrm{C}$. Staining of the cells was followed by washing them in the Perm/Wash Buffer. The excess of antibody was removed by washing in the Perm/Wash Buffer and analysis was performed using FACSCalibur flow cytometer (BD Biosciences). All experimental chemicals were purchased from BD Biosciences. The acquisition gates were restricted to cell gates based on morphological characteristics (FSC vs. SSC), and at least 30,000 cells were acquired and analyzed. The results are expressed as a percentage of the studied cell population.

Mitochondrial membrane depolarization assay. A total of $5 \times 10^{5}$ cells were suspended in the Stain Buffer and the MitoStatus Red solution was added to obtain the final concentration of $20 \mathrm{nM}$. The cells were incubated for $30 \mathrm{~min}$ at $37^{\circ} \mathrm{C}$ in the dark and then washed twice. Subsequently, $200 \mu \mathrm{l}$ of Stain Buffer was used to suspend the stained cells. Differences in mitochondrial membrane depolarization between the tested and control cells were assessed on a FACSCalibur flow cytometer (BD Biosciences). All experimental chemicals were purchased from BD Biosciences. The acquisition gates were restricted to cell gates based on morphological characteristics 
(FSC vs. SSC), and at least 20,000 cells were acquired and analyzed. The results are expressed as a percentage of the studied cell population.

Cell proliferation assay. Cell proliferation was measured by the CellTrace ${ }^{\mathrm{TM}}$ Cell Proliferation kit (Invitrogen; Thermo Fisher Scientific) according to the manufacturer's protocol. Briefly, $5 \times 10^{6}$ cells from colonospheres in suspension were incubated with $5 \mu \mathrm{M}$ CellTrace-carboxyfluoresceinsuccinimidyl ester (CFSE) Dye for $20 \mathrm{~min}$ at $37^{\circ} \mathrm{C}$ in the dark. Subsequently, the excess of unbound dye was removed by addition of culture medium and centrifugation. Pelleted cells were re-suspended in complete serum-free medium containing 5-FU, ASA anti-EGFR antibody or their combination and cultured for 3 days prior to analysis on a FACSCalibur flow cytometer (BD Biosciences). The acquisition gates were restricted to cell gates based on morphological characteristics (FSC vs. SSC), and at least 50,000 cells were acquired and analyzed. The results are expressed as a percentage of the studied cell population.

Cell cycle analysis in colonospheres. After culturing the colonospheres for 7 days, cells were washed twice in PBS (BD Biosciences), and $1 \times 10^{7}$ cells were fixed in $70 \%$ ethanol $(\mathrm{EtOH})$ at $-20^{\circ} \mathrm{C}$. After 2 weeks, $\mathrm{EtOH}$ was removed by centrifugation in $400 \mathrm{x} \mathrm{g}$ for $5 \mathrm{~min}$ at room temperature and cell pellet was washed with cold PBS $\left(400 \mathrm{x} \mathrm{g} ; 10 \mathrm{~min} ; 4^{\circ} \mathrm{C}\right)$ and resuspended in $450 \mu \mathrm{l}$ in staining buffer composed of PBS (Sigma-Aldrich), PI (50 $\mu \mathrm{g} / \mathrm{ml})$ (BD Biosciences) and RNase A $(25 \mu \mathrm{g} / \mathrm{ml})$ (Sigma-Aldrich), incubated for $30 \mathrm{~min}$ in the dark at $37^{\circ} \mathrm{C}$, and finally analyzed using a FACSCalibur flow cytometer (BD Biosciences). The acquisition gates were restricted to cell gates based on morphological characteristics (FSC vs. SSC), next pulse processing was used to exclude cell clumps and doublets from the analysis (FL-2A vs. FL-2W) and finally those gates were combined and applied to PI histogram plots.

Acridine orange staining. The morphological changes of the drug-treated cells were examined microscopically following acridine orange (AO) staining (Sigma-Aldrich). By AO staining, viable cells appear green, whereas early apoptotic cells stain green and show chromatin condensation or nuclear fragmentation presented as bright green dots in nuclei. When AO is protonated and trapped in acidic vesicular organelles (AVOs), it forms aggregates which emit bright red fluorescence in concentration-dependent manner. AO solution was prepared before use by mixing AO stock $(1 \mathrm{mg} / \mathrm{ml})$ with PBS (Sigma-Aldrich). Following drug treatment, the cells were washed and suspended in PBS. Fortyfive microliters of cell suspension was mixed gently with $5 \mu \mathrm{l}$ of AO solution to obtain a final concentration of $1 \mu \mathrm{g} / \mathrm{ml} \mathrm{AO}$. The samples were incubated for $15 \mathrm{~min}$ in the dark, placed onto microscopic poly-L-lysine-coated slides (Sigma-Aldrich) and covered with glass coverslips thereon. The slides were examined under a fluorescence microscope Nikon Eclipse E800 (Nikon).

Measurement of the presence of $\mathrm{COX}-2$. The expression of COX-2 in the stimulated and non-stimulated cells was determined by intracellular staining. Following fixation and permeabilization of cells, they were washed in Perm/Wash Buffer (BD Biosciences) and stained with monoclonal anti-COX-2-PE antibody $(\mathrm{IgG1}, \kappa)(565125$;
BD Biosciences). Following $30 \mathrm{~min}$ of incubation in the dark at room temperature, samples were fixed and prepared for cytometric analysis using a FACSCalibur flow cytometer (BD Biosciences).

COX-2 activity assay. COX-2 activity was measured using a fluorimetric Cyclooxygenase Activity Assay kit according to manufacturer's protocol (Abcam). Briefly, standards were prepared and read on a microplate reader Synergy H1 (BioTek). Next steps included preparation of COX Working Solution, Arachidonic Acid Working Solution and Reaction Mix as described in the protocol. Protein concentration in the lysates from spheres treated for $72 \mathrm{~h}$ with 5-FU, ASA, anti-EGFR antibody or their combination was measured with Bradford reagent (Sigma-Aldrich). On the 96 well ultra-low attachment plates combination of Reaction Buffer Mix, COX specific inhibitor, DMSO and cell lysates samples were added. Arachidonic Acid Solution was added to each well immediately before the read on a microplate reader. Fluorescence was measured at $\mathrm{Ex} / \mathrm{Em}=535 / 587 \mathrm{~nm}$ every $2 \mathrm{~min}$ for $1 \mathrm{~h}$. Each probe was prepared in duplicate. Standard curve was used to determine the activity of COX-2 in the samples.

Statistical analysis. Data were analyzed using the GraphPad Prism ver. 6.05 (GraphPad Software) and Statistica 12 software (Statsoft). The statistical significance of differences between mean values was based on non-parametric tests, such as Mann-Whitney U test or Kruskal-Wallis test followed by Dunn's multiple comparisons test as a post hoc procedure, moreover Spearman's rank coefficient was used to assess correlation. All data are presented as the means \pm standard error of the mean (SEM) based on at least 3 independent experiments.

\section{Results}

Morphology and size of colonospheres after treatment with drugs. Based on our preliminary experiments (data not shown) to establish the effective concentrations of the tested drugs and the results of other studies (12,30-33), in this study, we decided to use the following concentrations of the tested drugs: $50 \mu \mathrm{M}$ 5-FU, $1.5 \mathrm{mM}$ ASA and $20 \mu \mathrm{g} / \mathrm{ml}$ anti-EGFR antibody.

All the tested drugs produced visible changes in the morphology of spheres derived from both tested CRC cell lines. The HCT116 cell-derived spheres seemed to retain their characteristic outline even when the amount of dead cells and debris in the medium visibly increased following treatment with 5-FU, ASA and 5-FU + ASA (Fig. 1A). Notably, the colonospheres stimulated with anti-EGFR antibody, anti-EGFR antibody + 5-FU, and anti-EGFR antibody + ASA acquired a more swelled appearance. Moreover, the HCT116 cell-derived spheres treated with anti-EGFR antibody +5 -FU and anti-EGFR antibody + ASA were almost deprived of clearly visible dead cells, which were present in the absence of anti-EGFR antibody in the medium. The size of the HCT116 cell-derived colonospheres was significantly reduced when the cells were treated with used drugs and their combinations (Fig. 1B).

A similar analysis was performed for colonospheres derived from the HT29 CRC cell line (Fig. 2). The morphology of the spheres was markedly affected by all drugs and their 
A

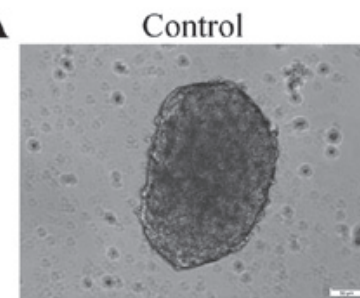

$5-\mathrm{FU}$

ASA

5-FU+ASA
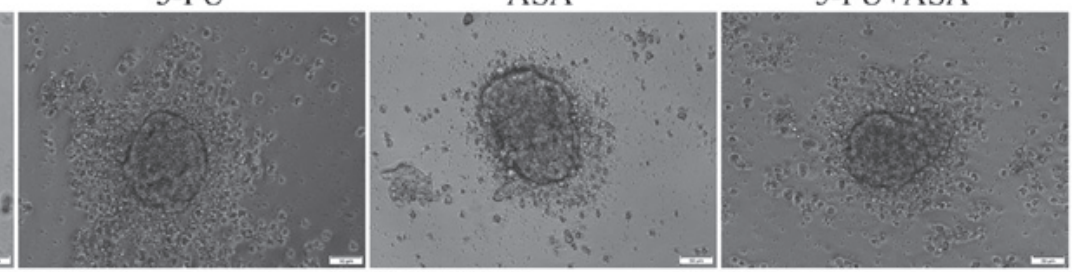

anti-EGFR+ASA

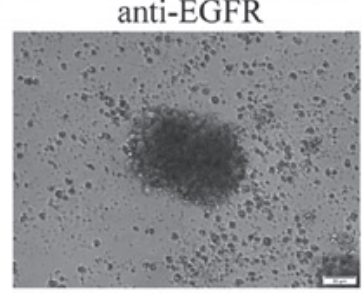

anti-EGFR+5-FU

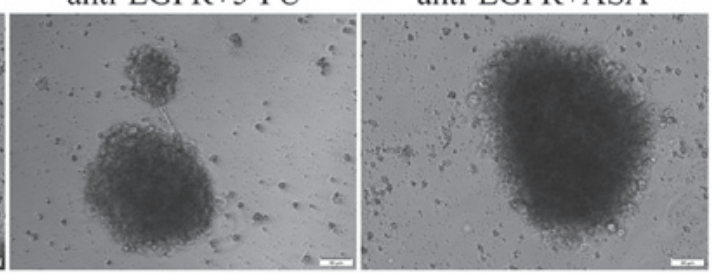

B

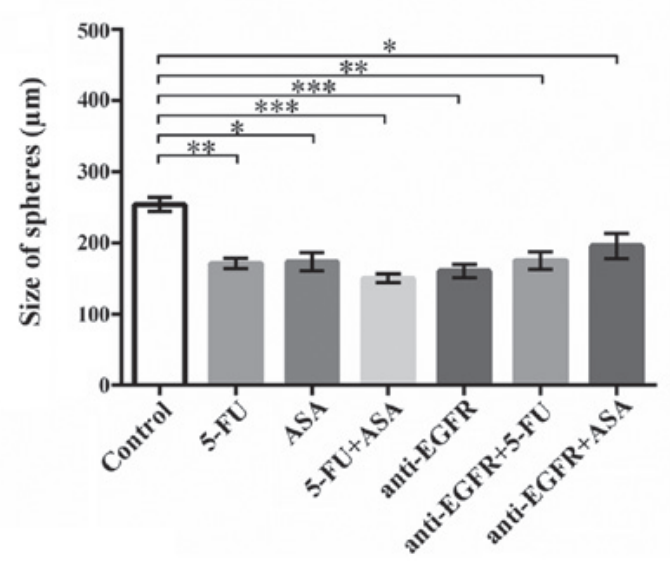

Figure 1. Effects of the drugs on the morphology and size of HCT116-derived colonospheres. HCT116-derived colonospheres were incubated with 5-FU, ASA anti-EGFR antibody and their combinations for 72 h. (A) Morphology of colonospheres cultured with the drugs. Scale bar, $50 \mu \mathrm{m}$. (B) Size of HCT116 cell-derived spheres following incubation with the drugs. Statistically significant differences assessed by Kruskal-Wallis test followed by Dunn's test as a post hoc procedure. ${ }^{*} \mathrm{P}<0.05,{ }^{* *} \mathrm{P}<0.001$ and ${ }^{* * *} \mathrm{P}<0.0001$. The number of replicates $\mathrm{N}$ for particular experiments were: $\mathrm{N}_{\mathrm{CONTROL}}=13, \mathrm{~N}_{5 \text {-FU }}=12, \mathrm{~N}_{\mathrm{ASA}}=10$, $\mathrm{N}_{5-\mathrm{FU}+\mathrm{ASA}}=13, \mathrm{~N}_{\text {anti-EGFR }}=24, \mathrm{~N}_{\text {anti-EGFR+5-FU }}=14, \mathrm{~N}_{\text {anti-EGFR+ASA }}=15$. All data are presented as the means \pm SEM. 5-FU, 5-fluorouracil; ASA, aspirin; EGFR, epidermal growth factor receptor.

combinations, with the most notable change being observed in the HT29 cell-derived colonospheres cultured with ASA, 5-FU + ASA, and anti-EGFR antibody (Fig. 2A). These evident structural changes were paralleled by the drug-induced reduction of spheres' diameter (Fig. 2B). The largest reduction in the size of the colonospheres was observed following their incubation with 5-FU + ASA and anti-EGFR antibody + ASA, while 5-FU or anti-EGFR alone were less effective. Notably, anti-EGFR antibody treatment alone did not decrease the size of the HT29 cell-derived colonospheres.

Additionally, to compare the sensitivity of the cells cultured in the adherent and spherical forms to the tested drugs, we conducted two independent experiments. First, we incubated adherent cells with 5-FU, ASA and anti-EGFR antibody, or their combinations for $72 \mathrm{~h}$ and the cells were then transferred into SCM to assess their ability to form colonospheres, which reflects their tumor-initiating capacity (Fig. 3A). Both CRC cell lines presented similar results; thus, we prepared a representative panel presenting data for only the HT29 cells cultured for 7 days in medium dedicated for CSC-like cells. After that time, untreated HT29 cells should form colonospheres with the typical morphology presented in Fig. 2. However, the pre-treated cells were evidently affected by the used agents and exhibited a reduced ability to create spheres (Fig. 3A). The formation of small clusters of aggregated cells was most evident for the ASA-pre-treated cells in comparison to the other incubations. In addition, the anti-EGFR antibodyand anti-EGFR antibody + 5-FU-pre-treated cultures apparently contained smaller amorphic spheres (rather than cell aggregates), whereas the 5-FU + ASA- and anti-EGFR antibody + ASA-pre-treated cells practically did not form colonospheres.

To determine the heterogeneity of the cells within spheres, we washed the cultures treated with the tested agents for $72 \mathrm{~h}$, and seeded the cell suspension in fresh SCM. After 7 days, we examined the effects of the agents on the 'secondary sphere' formation ability, reflecting the tumor-initiating capacity and susceptibility of the CSC-like cells to the used agents in both CRC lines. The results for both cell lines were similar; thus, we present a representative panel for the HT29 cell line only (Fig. 3B). The combination of 5-FU + ASA suppressed the re-formation of colonospheres to the highest degree. Notably, ASA and anti-EGFR antibody alone or in combination only slightly suppressed the re-aggregation of cells, as we observed many freely-floating spheres following such incubations. In general, the colonospheres of the both CRC cell lines analyzed 

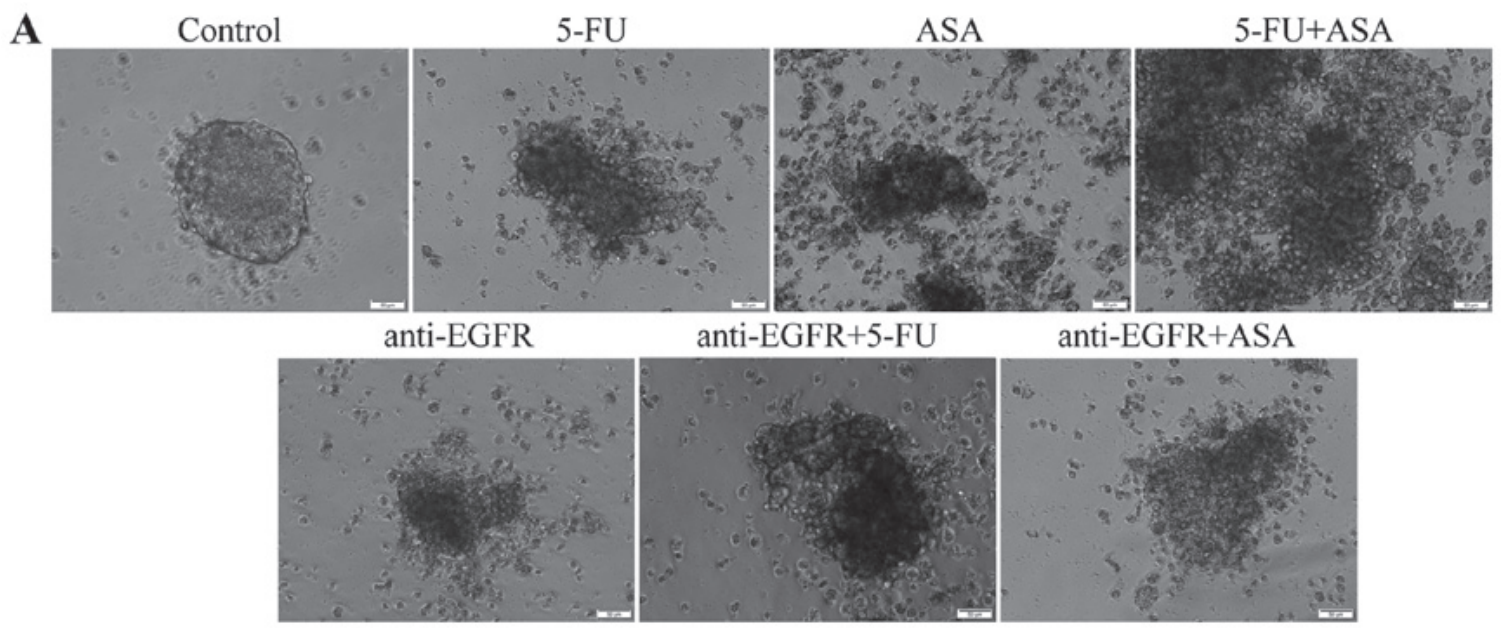

anti-EGFR+5-FU

anti-EGFR+ASA

B

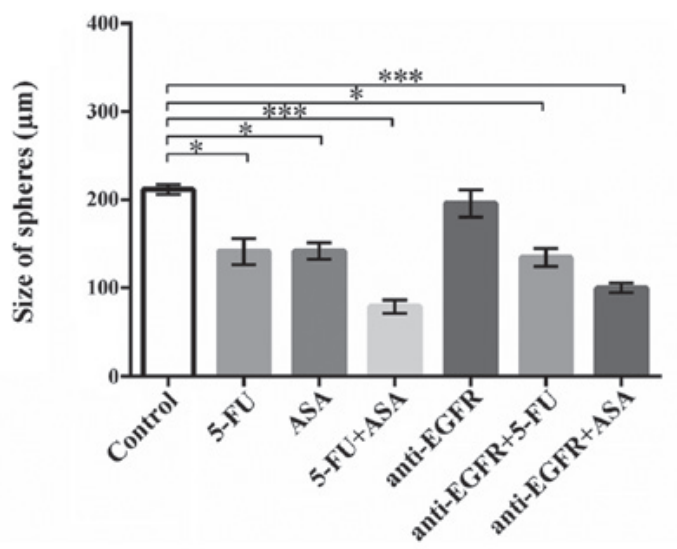

Figure 2. Effects of the drugs on the morphology and size of HT29-derived colonospheres. HT29-derived colonospheres were incubated with 5-FU, ASA, anti-EGFR and their combinations for 72 h. (A) Morphology of colonospheres cultured with the drugs. Scale bar, $50 \mu \mathrm{m}$. (B) Size of HT29 cell-derived spheres following incubation with the drugs. Statistically significant differences assessed by Kruskal-Wallis test followed by Dunn's test as a post hoc procedure. ${ }^{*} \mathrm{P}<0.05$ and ${ }^{* * *} \mathrm{P}<0.0001$. The number of replicates $\mathrm{N}$ for particular experiments were: $\mathrm{N}_{\mathrm{CONTROL}}=12, \mathrm{~N}_{5-\mathrm{FU}}=16, \mathrm{~N}_{\mathrm{ASA}}=16, \mathrm{~N}_{5-\mathrm{FU}+\mathrm{ASA}}=14, \mathrm{~N}_{\text {anti-EGFR }}=11$, $\mathrm{N}_{\text {anti-EGFR+5-FU }}=11, \mathrm{~N}_{\text {anti-EGFR+ASA }}=11$. All data are presented as the means \pm SEM. 5-FU, 5-fluorouracil; ASA, aspirin; EGFR, epidermal growth factor receptor.

presented a higher tumor-initiating capacity in comparison to their adherent cultures, suggesting that they are more resistant to the chemotherapy, probably due to the occurrence of more primitive and quiescent CSC-like cells.

Phenotypic analysis of colonospheres following drug treatment. The phenotypic analysis of the drug-treated spheres aimed to determine the fractions of putative CSC-like cells that express characteristic markers, such as CD133, CD29 and CD44 $(10,20)$. We observed a significant decrease in the percentage of $\mathrm{CD}_{133^{+}}$cells, a marker which was for the first time used to define CSC-like cells from CRC $(2,3)$, in HCT116 cell-derived spheres following incubation with the majority of the applied drugs. Surprisingly, neither 5-FU alone nor its combination with anti-EGFR antibody markedly affected the fraction of $\mathrm{CD}_{133^{+}}$cells (Fig. 4A). When the spherical population was analyzed with respect to the presence of CD29 and CD44 integrins, we noted a lack of changes in the CD29/CD44-positive cell population except for the HCT116 cells treated with anti-EGFR antibody + ASA, which presented an elevated percentage of CD29/CD44-positive cells in comparison to the control (Fig. 4B). The untreated HT29 cell-derived spheres presented a lower percentage of $\mathrm{CD}_{133^{+}}$cells than the HCT116 cell-derived spheres, as we have reported previously (10). Phenotypic analysis revealed a statistically significant decrease in the fraction of HT29-CD133+ only in the 5-FU + ASA-treated cells (Fig. 4C). Notably, none of the tested drugs markedly affected the CD29+CD44 ${ }^{+}$ fraction within the HT29-derived colonospheres (Fig. 4D). Phenotypic analysis confirmed that the CSC-like fraction was not vulnerable to the therapeutic agents since it was only slightly affected by the tested drugs.

Analysis of FasL and FasR expression in CRC spheres following drug treatment. Fas receptor (termed FasR), commonly known as the death receptor, and one of its ligands, FasL, may trigger the apoptotic process. However, recent studies have also suggested the non-apoptotic activity of this signaling pathway, not only to maintain the cellular homeostasis, but also the CSC-like population (34-37). Thus, in this study, we aimed to determine whether 5-FU, ASA, anti-EGFR antibody, and their combinations could affect the expression of FasL and FasR in the treated spherical cultures of the tested CRC cell lines.

We found that only the HCT116-derived colonospheres treated with ASA displayed a significantly lower number of $\mathrm{FasL}^{+}$cells in comparison to the untreated control $(85.5 \pm 5.4 \%)$, whereas the other drugs did not affect FasL expression compared to the control (Fig. 5A). When the FasR level was tested in the HCT116-derived colonospheres, no significant 

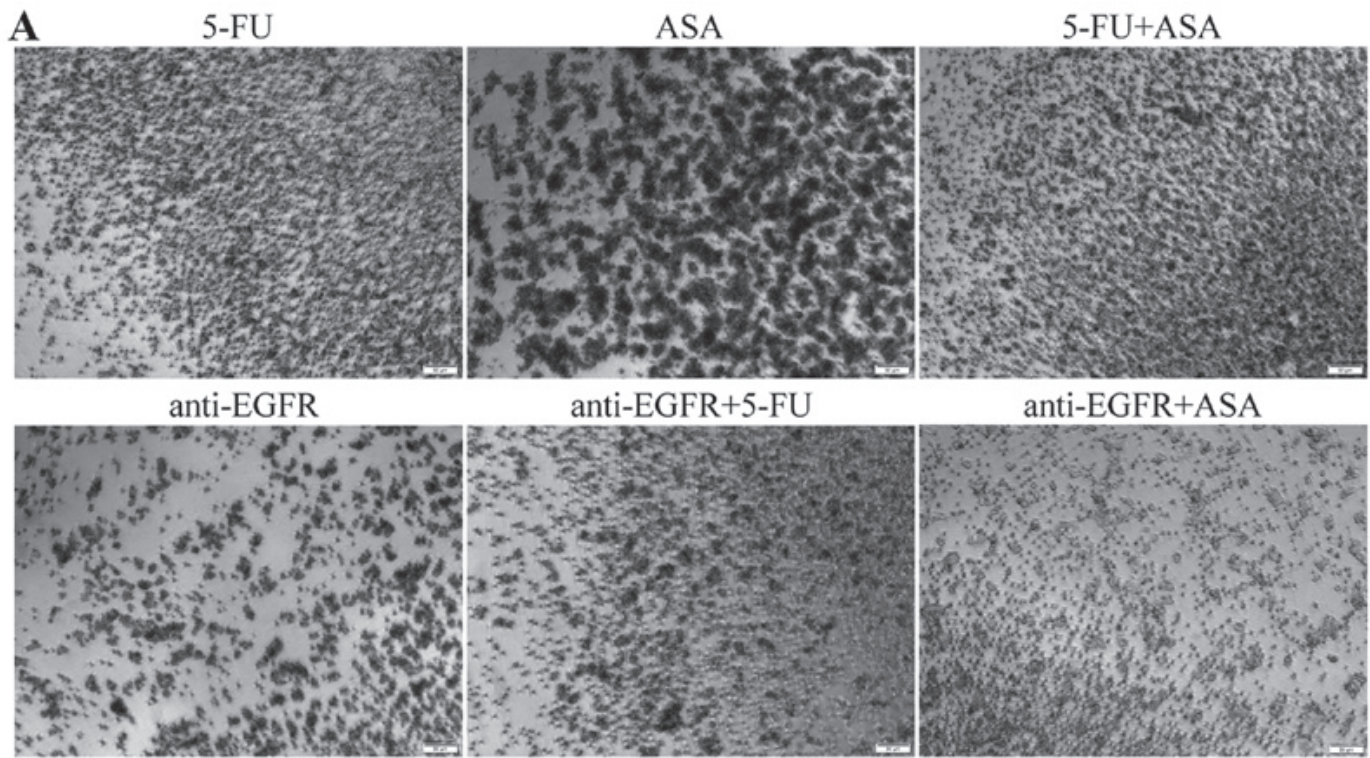

anti-EGFR+ASA
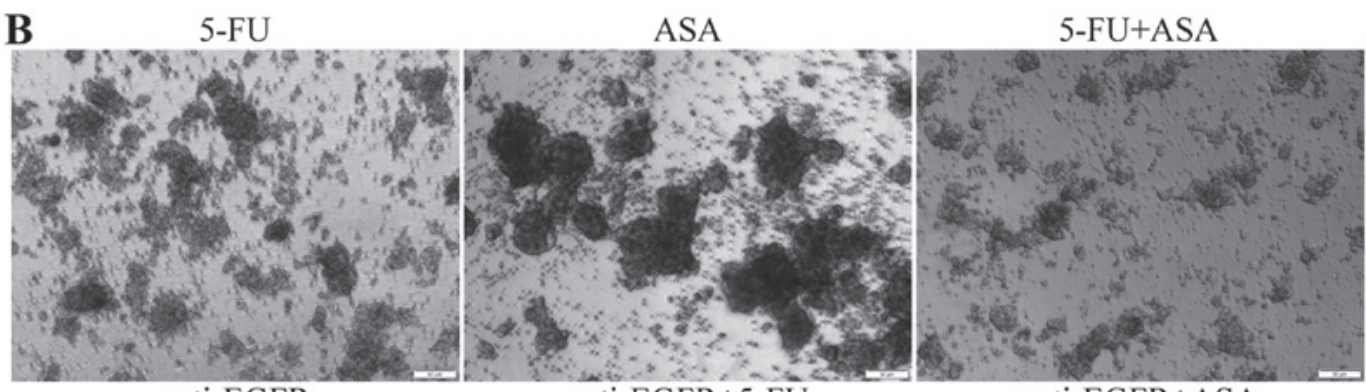

anti-EGFR

anti-EGFR+5-FU

anti-EGFR+ASA

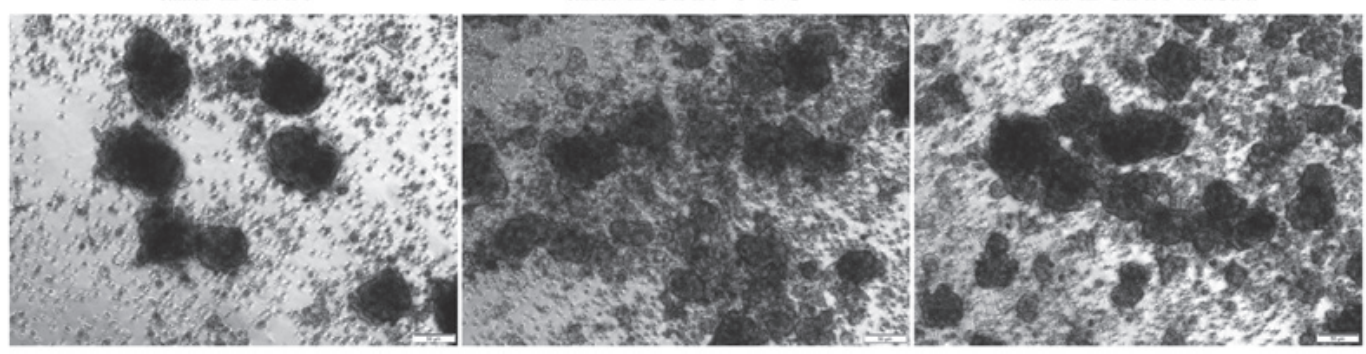

Figure 3. (A) Sphere formation capacity of HT29 cells pre-treated with 5-FU, ASA, anti-EGFR antibody and their combinations. Scale bar, $50 \mu \mathrm{m}$. (B) 'Secondary sphere' formation capacity of HT29-primary spheres treated with 5-FU, ASA, anti-EGFR and their combinations. Scale bar, 50 $\mu \mathrm{m}$. 5-FU, 5-fluorouracil; ASA, aspirin; EGFR, epidermal growth factor receptor.

alterations in the percentage of FasR-expressing cells were noted following treatment with the tested drugs in comparison to the unstimulated cells (Fig. 5B).

We found that in the HT29-derived colonospheres, $91.2 \pm 8.6 \%$ of the control cells were $\mathrm{FasL}^{+}$whereas 5-FU + ASA stimulation significantly decreased that number to $84.3 \pm 1.3 \%$ (Fig. 5C). Notably, the combination of ASA with anti-EGFR antibody was not as effective and abolished the suppressive effect of ASA. In general, the HT29 cell-derived spheres contained a high fraction of FasL-positive cells, while the percentage of cells exhibiting FasR on their surface was extremely low and did not exceed 6\% (Fig. 5D). Moreover, the HT29 cell line seemed to be more sensitive to anti-EGFR antibody and its combination with 5-FU or ASA treatment; thus, only these drugs diminished the $\mathrm{FasR}^{+}$population.

Viability of the HCT116 derived-colonospheres following drug treatment. We evaluated the percentage of non-viable cells following incubation with the agents in both cultured CRC cell lines by flow cytometry using 7-AAD dye. 7-AAD is excluded from viable cells, but binds selectively to GC regions of the DNA of damaged cells. Statistical analysis revealed that the viability of the HCT116-derived colonospheres was not affected by incubation with each of the drugs alone; however, the combinations of the agents significantly decreased the viability (Fig. 6A).

To assess whether the changes in the percentage of non-viable cells are caused by apoptosis, we measured the presence of a key protease activated during the process, i.e., active caspase- 3 . The HCT116 cell-derived control population presented $17.5 \pm 4.7 \%$ of cells expressing an active form of caspase-3. Although a reductive tendency was observed for all drugs, apart from 5-FU, statistical analysis revealed that the fraction of caspase-3-positive cells decreased when the HCT116-derived colonospheres were

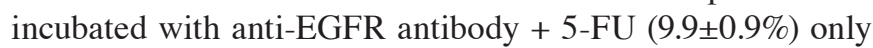
compared to the control (Fig. 6B). 
A

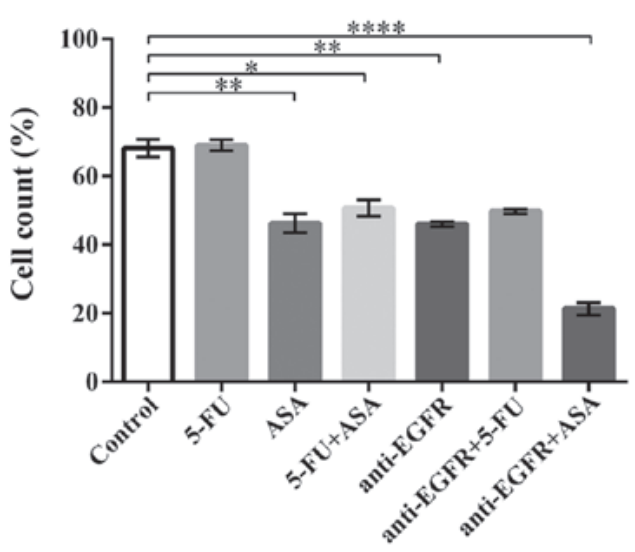

B $\mathrm{HCT} 116^{-} \mathrm{CD} 44^{+} \mathrm{CD} 29^{+} \mathrm{CD} 133^{-}$

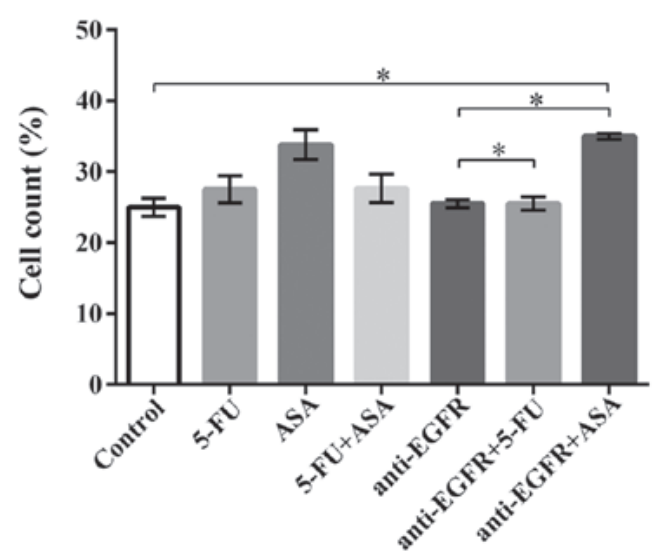

C HT29-CD133 $^{+}$

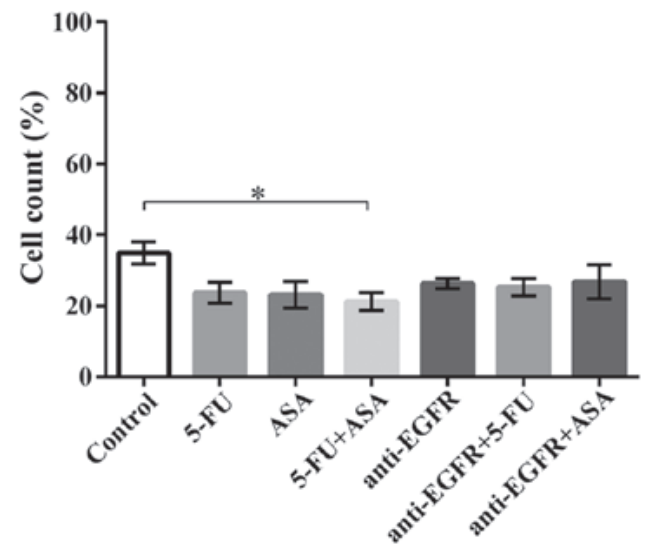

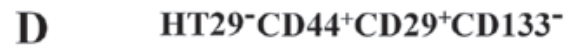

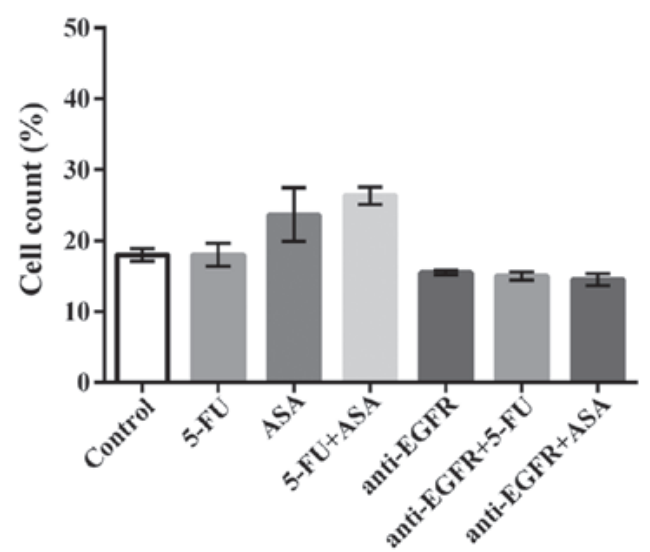

Figure 4. The phenotype of cells present in colonospheres derived from the HCT116 and HT29 CRC cell lines cultured with the drugs for 72 h. (A and C) The percentage of cells expressing the CSC marker, CD133, in HCT116 cell- and HT29 cell-derived spheres, respectively. The number of replicates N for particular experiments with HCT116-derived colonospheres were: $\mathrm{N}_{\mathrm{CONTROL}}=14, \mathrm{~N}_{5-\mathrm{FU}}=12, \mathrm{~N}_{\mathrm{ASA}}=12, \mathrm{~N}_{5-\mathrm{FU}+\mathrm{ASA}}=12, \mathrm{~N}_{\text {anti-EGFR }}=6, \mathrm{~N}_{\text {anti-EGFR }+5 \text {-FU }}=8, \mathrm{~N}_{\text {anti-EGFR+ASA }}=6$. For HT29-derived colonospheres: $\mathrm{N}_{\mathrm{CONTROL}}=8, \mathrm{~N}_{5-\mathrm{FU}}=6, \mathrm{~N}_{\mathrm{ASA}}=6, \mathrm{~N}_{5-\mathrm{FU}+\mathrm{ASA}}=6, \mathrm{~N}_{\text {anti-EGFR }}=6, \mathrm{~N}_{\text {anti-EGFR }+5 \text {-FU }}=6, \mathrm{~N}_{\text {anti-EGFR+ASA }}=6 .(\mathrm{B}$ and D) The percentage of cells expressing the CSC markers, CD44 and CD29, in HCT116 cell- and HT29 cell-derived colonospheres, respectively. For HCT116-derived colonospheres: $\mathrm{N}_{\text {CONTROL }}=8, \mathrm{~N}_{5-\mathrm{FU}}=12, \mathrm{~N}_{\mathrm{ASA}}=12, \mathrm{~N}_{5-\mathrm{FU}+\mathrm{ASA}}=12, \mathrm{~N}_{\text {anti=EGFR }}=8, \mathrm{~N}_{\text {anti }=\mathrm{EGFR}+5-\mathrm{FU}}=8, \mathrm{~N}_{\text {anti }=\text { EGFR }+ \text { ASA }}=8$. For HT29-derived colonospheres: $\mathrm{N}_{\mathrm{CONTROL}}=10, \mathrm{~N}_{5-\mathrm{FU}}=6$, $\mathrm{N}_{\mathrm{ASA}}=6, \mathrm{~N}_{5-\mathrm{FU}+\mathrm{ASA}}=6, \mathrm{~N}_{\text {anti-EGFR }}=6, \mathrm{~N}_{\text {anti-EGFR }+5-\mathrm{FU}}=6, \mathrm{~N}_{\text {anti-EGFR+ASA }}=6$. Cells were analyzed by flow cytometry. Statistically significant differences assessed by Kruskal-Wallis test followed by Dunn's test as a post hoc procedure. ${ }^{*} \mathrm{P}<0.05,{ }^{* *} \mathrm{P}<0.005$ and ${ }^{* * * *} \mathrm{P}<0.0005$. All data are presented as the means $\pm \mathrm{SEM}$. 5-FU, 5-fluorouracil; ASA, aspirin; EGFR, epidermal growth factor receptor.

An-V and PI staining was used to determine the fractions of apoptotic and necrotic cells. In contrast to active caspase-3 expression, An-V staining detects cells with phosphatidylserine in the extracellular layer of cell membrane, one of the basic features of the apoptosis, while PI penetrates cells with more permeable plasma membrane. The incubation of the HCT116-derived colonospheres with anti-EGFR antibody +5 -FU and anti-EGFR antibody + ASA, but not with the other drugs or their combinations, increased the percentage of apoptotic cells compared to the control (Fig. 6C). The simultaneous staining with An-V and PI revealed that the control HCT116-derived colonospheres contained $9.2 \pm 1.9 \%$ of necrotic cells $\left(\right.$ Ann- $\left.-\mathrm{V}^{-} \mathrm{PI}^{+}\right)$. Surprisingly, none of the tested drugs or their combinations affected the percentage of necrotic cells compared to the control (Fig. 6D).

Subsequently, we decided to evaluate the involvement of mitochondria which play a crucial role in the apoptosis process. We used a fluorescent dye, MitoStatus Red, that is readily sequestered by active mitochondria, allowing for flow cytometric assessment of internal mitochondrial membrane depolarization that results in diminished levels of fluorescence. The fraction of HCT116 cells with a depolarized membrane $(\Delta \psi \mathrm{m})$ increased following treatment. Surprisingly, the percentage of intensively stained cells following incubation with each of the analyzed agents was highly increased in comparison to the unstimulated HCT116 control cells (R3 gate) (Fig. 8).

Viability of HT29-derived colonospheres following drug treatment. The most notable gain of $7-\mathrm{AAD}^{+}$cells was revealed when the HT29 cell-derived spheres were stimulated with the drug combinations, such as 5-FU + ASA, anti-EGFR antibody + 5-FU, and anti-EGFR antibody + ASA (Fig. 7A). ASA combined with anti-EGFR antibody triggered a greater increase of the non-viable cell fraction than the singly-applied agents (Fig. 7A). When we compared the percentage of cells exposing an active caspase-3, we found a significant decrease following stimulation with anti-EGFR antibody and its combination with 5-FU and ASA in comparison to the untreated HT29-derived colonospheres $(8.5 \pm 0.5 \%$, 
A
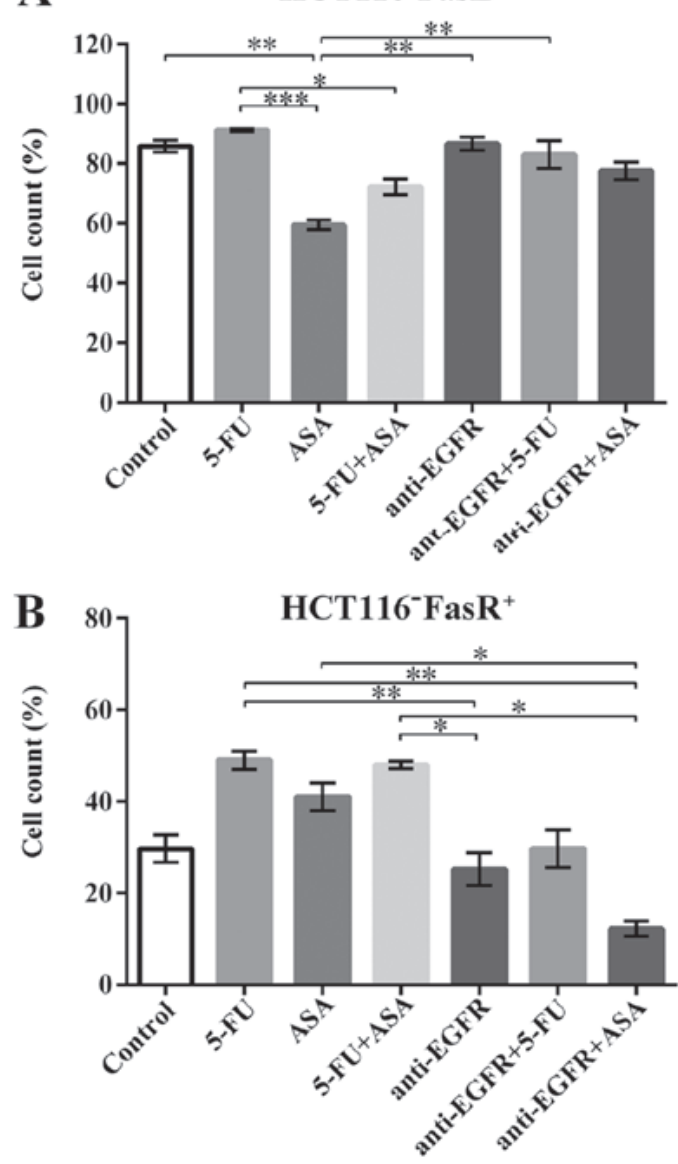

C

HT29-FasL $^{+}$
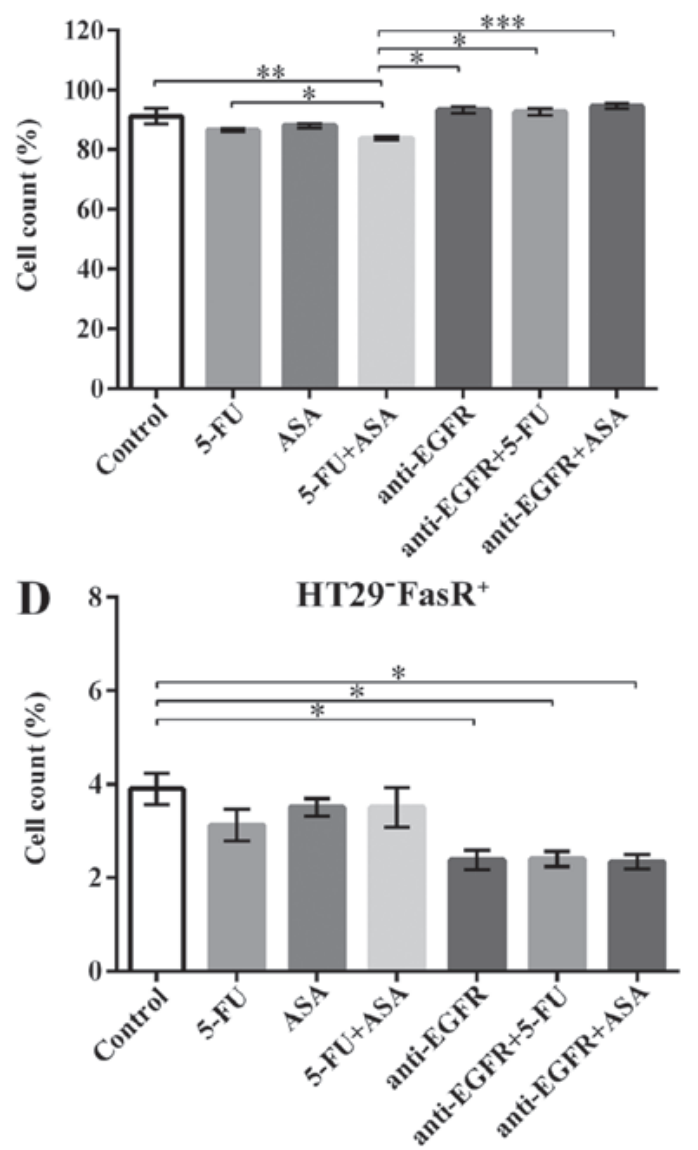

Figure 5. Effect of the drugs on the FasL and FasR presence on the surface of HCT116 and HT29 cells cultured with 5-FU, ASA, anti-EGFR antibody, and their combinations. (A and C) The percentage of FasL-positive cells in HCT116- and HT29-cells, respectively, quantified by flow cytometry. The number of replicates $\mathrm{N}$ for particular experiments with HCT116-derived colonospheres were: $\mathrm{N}=8$. For HT29-derived colonospheres: $\mathrm{N}_{\mathrm{CONTROL}}=10$, $\mathrm{N}_{5 \text {-FU }}=8$, $\mathrm{N}_{\mathrm{ASA}}=8, \mathrm{~N}_{5-\mathrm{FU}+\mathrm{ASA}}=8, \mathrm{~N}_{\text {anti-EGFR }}=9, \mathrm{~N}_{\text {anti-EGFR+5-FU }}=9, \mathrm{~N}_{\text {anti-EGFR+ASA }}=9$. (B and D) The percentage of FasR-positive cells in HCT116 cells and HT29 cells, respectively, quantified by flow cytometry. For HCT116-derived colonospheres: $\mathrm{N}_{\text {CONTROL }}=10, \mathrm{~N}_{5-\mathrm{FU}}=8, \mathrm{~N}_{\mathrm{ASA}}=8, \mathrm{~N}_{5-\mathrm{FU}+\mathrm{ASA}}=8, \mathrm{~N}_{\text {anti-EGFR }}=8, \mathrm{~N}_{\text {anti-EGFR } 5 \text {-FU }}=8$, $\mathrm{N}_{\text {anti-EGFR+ASA }}=8$. For HT29-derived colonospheres: $\mathrm{N}_{\mathrm{CONTROL}}=10, \mathrm{~N}_{5-\mathrm{FU}}=8, \mathrm{~N}_{\mathrm{ASA}}=8, \mathrm{~N}_{5-\mathrm{FU}+\mathrm{ASA}}=8, \mathrm{~N}_{\text {anti-EGFR }}=8, \mathrm{~N}_{\text {anti-EGFR+5-FU }}=8, \mathrm{~N}_{\text {anti-EGFR+ASA }}=8$. Statistically significant differences assessed by Kruskal-Wallis test followed by Dunn's test as a post hoc procedure. ${ }^{*} \mathrm{P}<0.05$, ${ }^{* *} \mathrm{P}<0.005$ and ${ }^{* * * *} \mathrm{P}<0.0005$. All data presented as the means \pm SEM. 5-FU, 5-fluorouracil; ASA, aspirin; EGFR, epidermal growth factor receptor.

$10.5 \pm 0.5 \%, 11.5 \pm 0.5 \%$ vs. $40.3 \pm 3.3 \%$, respectively) (Fig. $7 \mathrm{~B})$ Of note, An-V-PI staining revealed a significant increase in the apoptotic cell fraction following incubation with anti-EGFR antibody + 5-FU and anti-EGFR antibody + ASA in comparison to both 5-FU and ASA alone (Fig. 7C), what was related to a decrease in the necrotic cell fraction (Fig. 7D). Notably, the ASA- and 5-FU + ASA-stimulated HT29-derived colonospheres displayed an increase in necrotic cells by $26.3 \pm 7.2$ and $28.0 \pm 4.2 \%$, respectively, in comparison to the control (14.3 $\pm 2.1 \%)$; however, these alterations were not statistically significant compared to the control (Fig. 7D). We also found that the cellular fraction with a depolarized internal mitochondrial membrane was only slightly affected by the tested drugs. Although all of the tested agents reduced the number of intensively stained cells (even more than that of the control cells), only anti-EGFR antibody alone and in combination with 5-FU or ASA affected the distribution of cells by eradication of that population (R3 gate) (Fig. 8).

Effects of the tested agents on the proliferation and cell cycle distribution of the HCT116- and HT29-derived colonospheres. The proliferative capacity of the stimulated colonospheres obtained from both CRC cell lines was assessed by CFSE-based proliferation assay. CFSE diffuses into cells and binds covalently to cellular amine residues, and thereon it emits fluorescence proportional to the number of stained cells. Changes in the CFSE median fluorescence intensity (MFI) after 3 days of incubation of the spheres with the drugs relative to the MFI observed at day 0 represent fold increase related to the rate of proliferation (Fig. 9A and D).

The HCT116 cell-derived spheres treated with the majority of the tested drugs exhibited an elevated rate of proliferation in comparison to the control cells (Fig. 9A). The proliferation rate was the highest when the cells were treated with anti-EGFR antibody and its combination with 5-FU or ASA. Of note, we found that following single-agent treatment, the percentage of actively dividing cells increased significantly, whereas the combinations of two tested agents did not significantly alter the proliferation rate, apart from anti-EGFR antibody $+5-\mathrm{FU}$, although an increasing tendency was evident (Fig. 9B).

In addition to the CFSE-based proliferation assay, we performed cell cycle analysis. Compared to the control, treatment with 5-FU, 5-FU + ASA, and anti-EGFR antibody + ASA significantly decreased the number of cells accumulated in the $G_{0} / G_{1}$ phase (Fig. 9C), which is postulated as a phase 
A
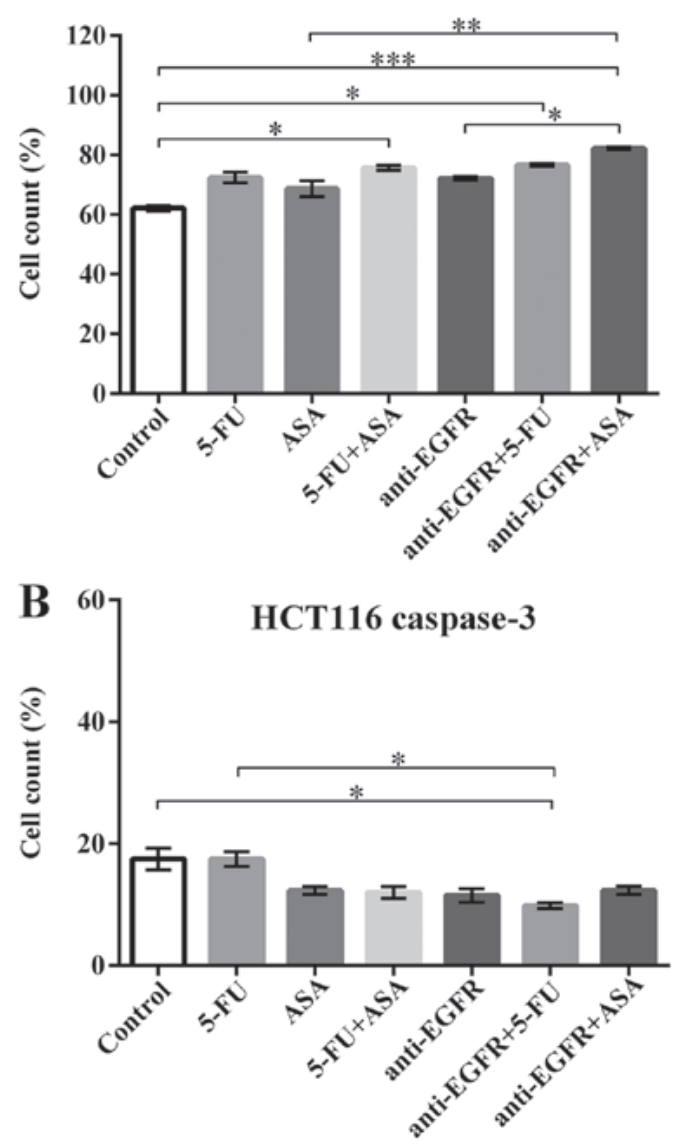

C HCT116 apoptotic cells
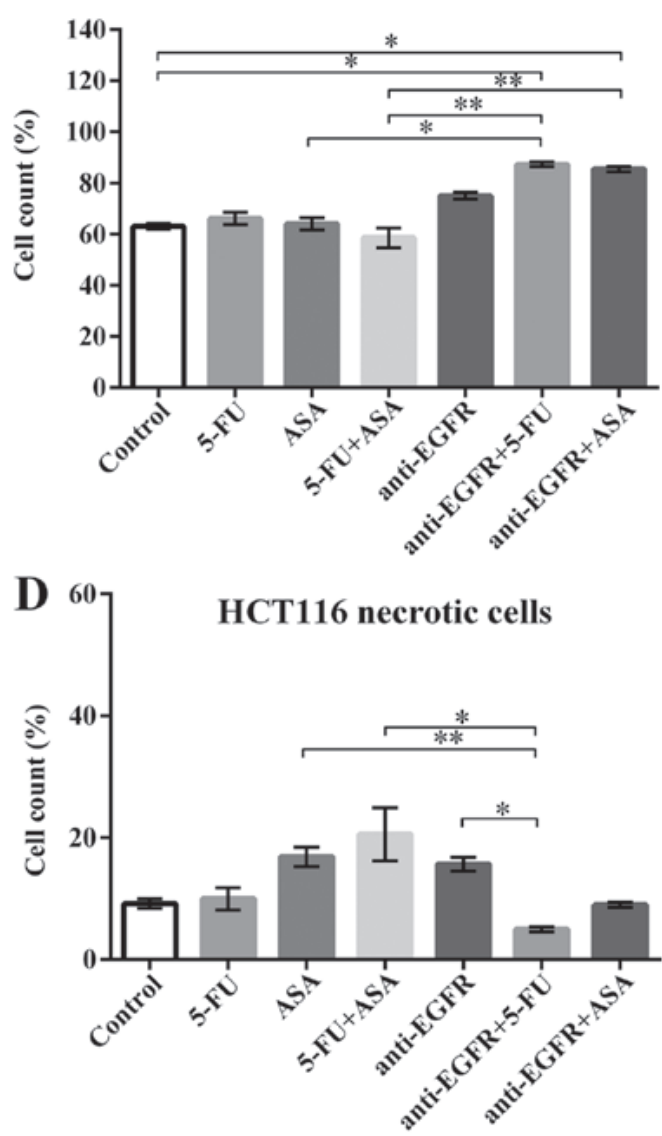

Figure 6. Effects of drugs on various measures of viability of HCT116-derived colonospheres. (A) 7-AAD staining of HCT116 cell-derived spheres. The number of replicates $\mathrm{N}=6$. (B) The expression of caspase-3 in HCT116 cell-derived spheres. The number of replicates $\mathrm{N}$ for particular experiments were: $\mathrm{N}_{\text {CONTROL }}=8, \mathrm{~N}_{5-\mathrm{FU}}=8, \mathrm{~N}_{\mathrm{ASA}}=12, \mathrm{~N}_{5-\mathrm{FU}+\mathrm{ASA}}=10, \mathrm{~N}_{\text {anti-EGFR }}=6, \mathrm{~N}_{\text {anti-EGFR }+5 \text {-FU }}=6, \mathrm{~N}_{\text {anti-EGFR+ASA }}=6$. (C) Annexin-V (An) and PI staining of apoptotic cells within HCT116 cell-derived spheres. $\mathrm{N}_{\mathrm{CONTROL}}=6, \mathrm{~N}_{5-\mathrm{FU}}=7, \mathrm{~N}_{\mathrm{ASA}}=5, \mathrm{~N}_{5-\mathrm{FU}+\mathrm{ASA}}=7, \mathrm{~N}_{\text {anti-EGFR }}=5, \mathrm{~N}_{\text {anti-EGFR }+5 \text {-FU }}=5, \mathrm{~N}_{\text {anti-EGFR+ASA }}=5$. (D) The percentage of necrotic (An-PI+) cells within HCT116 cell-derived spheres. $\mathrm{N}_{\mathrm{CONTROL}}=6, \mathrm{~N}_{5-\mathrm{FU}}=7, \mathrm{~N}_{\mathrm{ASA}}=5, \mathrm{~N}_{5-\mathrm{FU}+\mathrm{ASA}}=7, \mathrm{~N}_{\text {anti-EGFR }}=5, \mathrm{~N}_{\text {anti-EGFR+5-FU }}=5, \mathrm{~N}_{\text {anti-EGFR+ASA }}=5$. Statistically significant differences assessed by Kruskal-Wallis test followed by Dunn's test as a post hoc procedure. ${ }^{*} \mathrm{P}<0.05$, ${ }^{* *} \mathrm{P}<0.005$ and ${ }^{* * * *} \mathrm{P}<0.0005$. All data presented as the means \pm SEM. 5-FU, 5-fluorouracil; ASA, aspirin; EGFR, epidermal growth factor receptor.

housing dormant/quiescent CSC-like cells. Of note, a strong negative correlation was observed between the proliferation rate (CSFE-based assay) and the fraction of cells in the $\mathrm{G}_{0} / \mathrm{G}_{1}$-phase following treatment with anti-EGFR antibody + ASA (Spearman's rank correlation coefficient, $\mathrm{R}=-0.86, \mathrm{P}<0.05$ ), indicating the reduction of dormant CSC-like cells in favor of actively proliferating cells (Fig. S1).

The HT29-derived colonospheres presented a lower rate of proliferation in comparison to the HCT116-derived colonospheres (Fig. 9D), as we have reported previously (10). Moreover, the HT29 cells cultured with the agents displayed varying patterns of cellular division than the HCT116-derived colonospheres, since the HT29-derived colonospheres exhibited a lower percentage of dividing cells following treatment (Fig. 9E). In contrast to the HCT116-derived colonospheres, neither treatment with single agents nor with their combinations affected the distribution of cells in the cell cycle (Fig. 9F). The proportion of HT29 cells in the $G_{0} / G_{1}$ phase was similar to that of the HCT116 cells and was independent of the tested agent, apart from ASA, which reduced the fraction of HT29 cells in the $\mathrm{G}_{0} / \mathrm{G}_{1}$ phase compared to the control (Fig. 9F).
Analysis of autophagy induced in ASA and 5-FU + ASA-treated colonospheres. While culturing the colonospheres with drugs, we observed morphological changes in the studied CRC celllines. The HT29 cell-derived spheres, but not the HCT116-derived colonospheres, treated with ASA and 5-FU + ASA contained cells whose cytoplasm housed vesicles and bright halo-like rings. To determine the process/es responsible for these morphological changes, we performed AO staining of the treated colonospheres. AO is a cell-penetrating green fluorophore which upon protonation and trapping in acidic vesicular organelles (AVOs) (such as autolysosomes), forms aggregates that emit bright red fluorescence in a concentration-dependent manner, whereas cellular cytoplasm remains green. We found that incubation of the colonospheres derived from HT29 cells, but not from HCT116 cells, with 5-FU, ASA and 5-FU + ASA influenced the autophagy process. The HT29 cell-derived spheres treated with ASA and 5-FU + ASA contained a greater number of clearly visible AVOs in comparison to the control, while 5-FU did not markedly affect this amount (Fig. 10). In compliance with AO staining, a single repetition of western blot analysis of the LC3-I/II level [microtubule-associated protein 1A/1B-light chain 3 (LC3), which plays a critical role in 
A

HT29-7-AAD

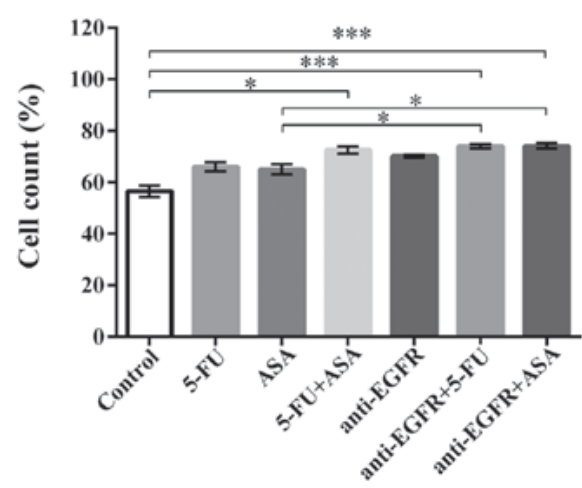

B

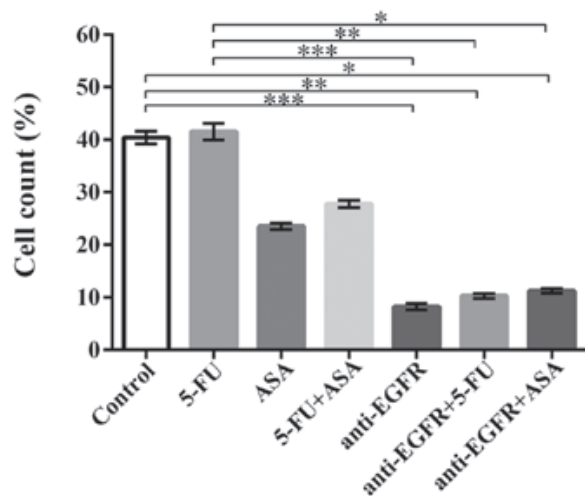

C

HT29 apoptotic cells

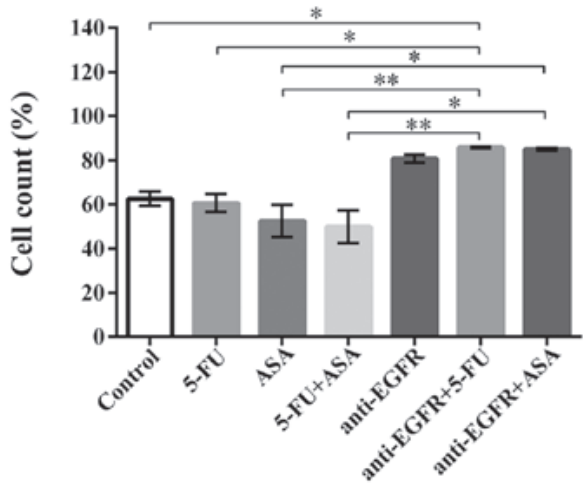

D

HT29 necrotic cells

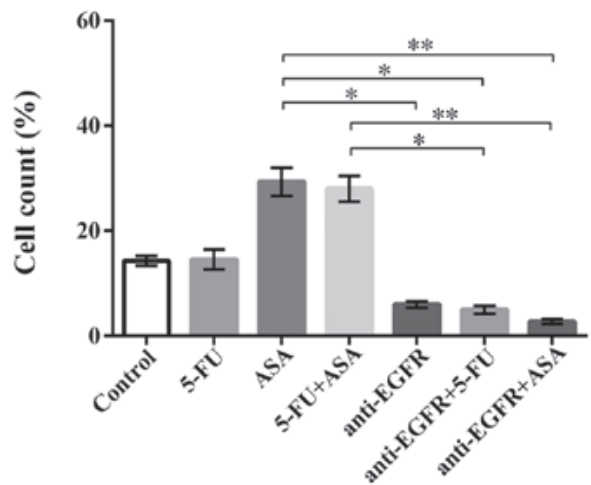

Figure 7. Effects of drugs on various measures of viability of HT29-derived colonospheres. (A) 7-AAD staining of HT29-spheres. The number of replicates $\mathrm{N}=6$. (B) The expression of caspase-3 in HT29 cell-derived spheres. The number of replicates $\mathrm{N}$ for particular experiments were: $\mathrm{N}_{\mathrm{CONTROL}}=8, \mathrm{~N}_{5-\mathrm{FU}}=10$, $\mathrm{N}_{\mathrm{ASA}}=8, \mathrm{~N}_{5-\mathrm{FU}+\mathrm{ASA}}=8, \mathrm{~N}_{\text {anti-EGFR }}=6, \mathrm{~N}_{\text {anti-GGFR+5-FU }}=6, \mathrm{~N}_{\text {anti-FGFR }+A S A}=6$. (C) Annexin-V (An) and PI staining of apoptotic cells within HT29 cell-derived spheres. $\mathrm{N}_{\text {CONTROL }}=8, \mathrm{~N}_{5-\mathrm{FU}}=8, \mathrm{~N}_{\mathrm{ASA}}=8, \mathrm{~N}_{5-\mathrm{FU}+\mathrm{ASA}}=7, \mathrm{~N}_{\text {anti-EGFR }}=5, \mathrm{~N}_{\text {anti-EGFR+5-FU }}=5, \mathrm{~N}_{\text {anti-EGFR+ASA }}=5$. (D) The percentage of necrotic (An PI f $_{+}$cells within HT29 cell-derived spheres. $\mathrm{N}_{\text {CONTROL }}=8, \mathrm{~N}_{5-\mathrm{FU}}=8, \mathrm{~N}_{\mathrm{ASA}}=8, \mathrm{~N}_{5-\mathrm{FU}+\mathrm{ASA}}=7$, NantiEGFR $=5, \mathrm{~N}_{\text {anti-EGFR+5-FU }}=5, \mathrm{~N}_{\text {anti-EGFR+ASA }}=5$. Statistically significant differences assessed by Kruskal-Wallis test followed by Dunn's test as a post hoc procedure. ${ }^{*} \mathrm{P}<0.05,{ }^{* *} \mathrm{P}<0.005$ and ${ }^{* * * *} \mathrm{P}<0.0005$. All data presented as the means $\pm \mathrm{SEM}$. 5-FU, 5-fluorouracil; ASA, aspirin; EGFR, epidermal growth factor receptor.

HCT116

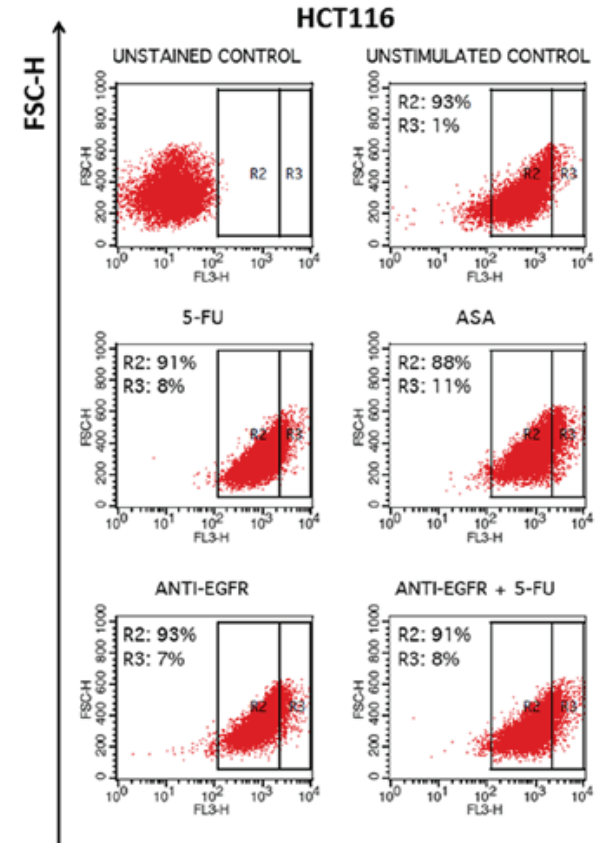

HT29
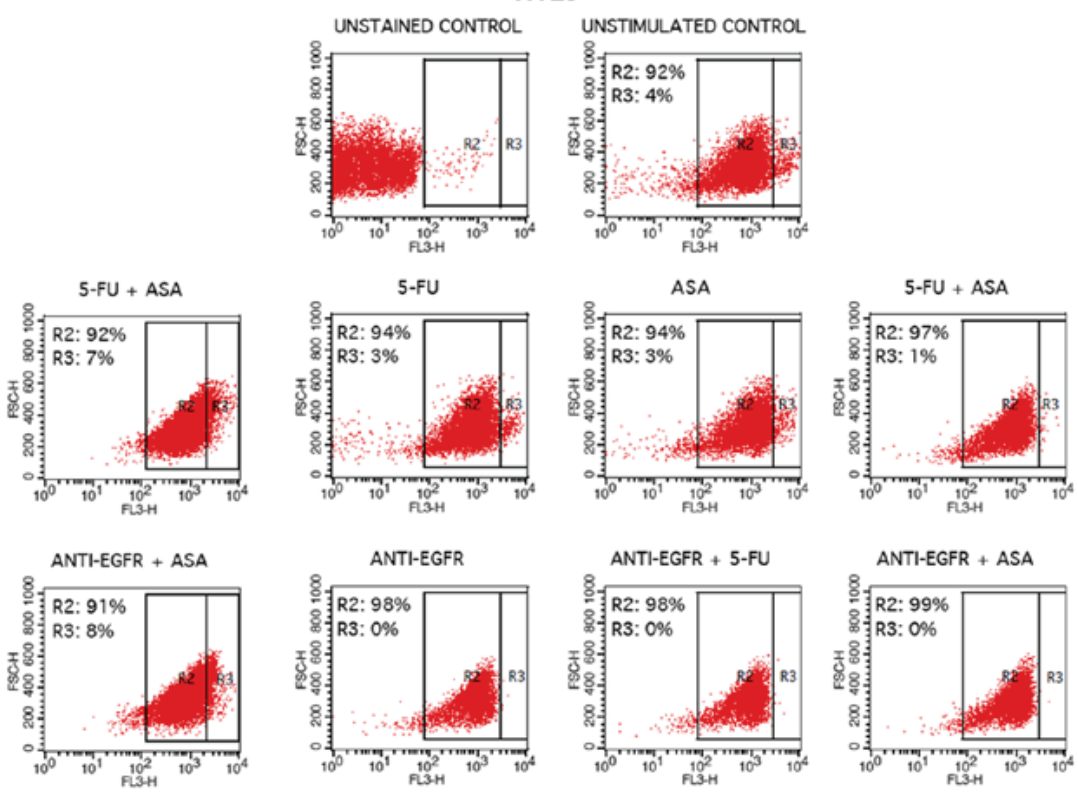

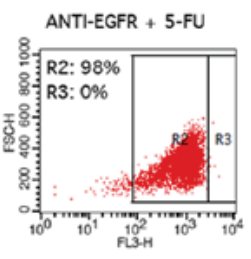

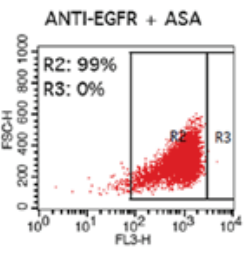

FL3-H MitoStatus red

Figure 8. Effects of drugs on the inner mitochondrial membrane depolarization in HCT116- and HT29-derived colonospheres. Cells with depolarized mitochondria showed diminished levels of MitoStatus Red fluorescence as assessed by flow cytometry. Representative plots for both HCT116- and HT29-derived clonospheres are presented in the panel. The number of replicates N=3.5-FU, 5-fluorouracil; ASA, aspirin; EGFR, epidermal growth factor receptor. 

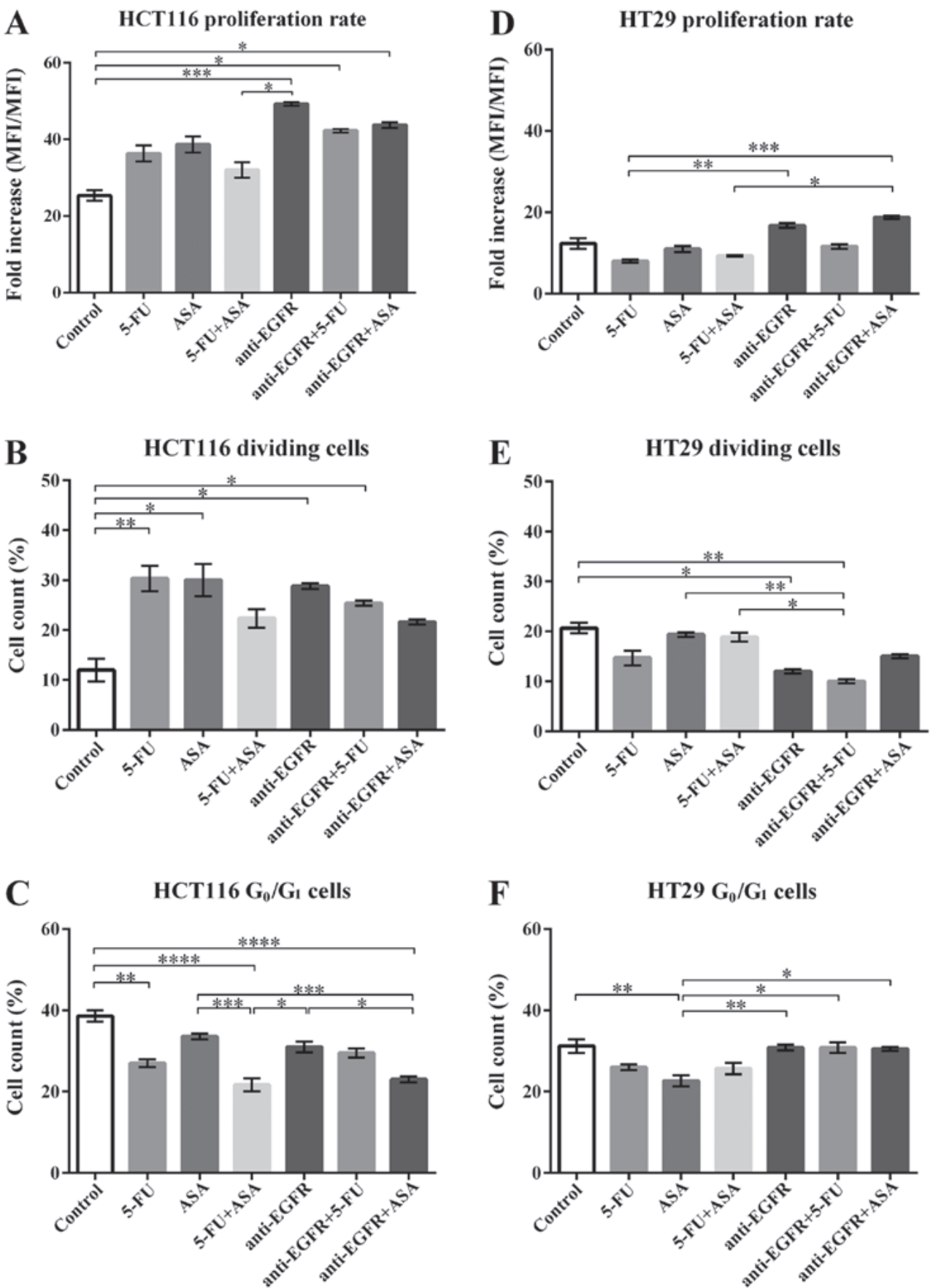

Figure 9. Effects of drugs on the proliferative capabilities of HCT116- and HT29-derikved colonospheres. (A and D) The fold increase of CFSE-MFI following drug treatment in HCT116- and HT29-derived spheres, respectively. The number of replicates N for particular experiments with HCT116 cell- and HT29 cell-derived spheres were: $\mathrm{N}_{\mathrm{CONTROL}}=6, \mathrm{~N}_{5-\mathrm{FU}}=6, \mathrm{~N}_{\mathrm{ASA}}=6, \mathrm{~N}_{5-\mathrm{FU}+\mathrm{ASA}}=6, \mathrm{~N}_{\text {anti-EGFR }}=5, \mathrm{~N}_{\text {anti-EGFR+5-FU }}=5, \mathrm{~N}_{\text {anti-EGFR+ASA }}=5$. (B and E) The proportions of HCT116 and HT29 cells, respectively, which underwent cellular divisions and presented decreased fluoresce of CFSE. For HCT116 and HT29 spheres: $\mathrm{N}_{\text {CONTROL }}=6, \mathrm{~N}_{5-\mathrm{FU}}=6, \mathrm{~N}_{\mathrm{ASA}}=6, \mathrm{~N}_{5-\mathrm{FU}+\mathrm{ASA}}=6, \mathrm{~N}_{\text {anti-EGFR }}=5$, NantiEGFR+5-FU $=5, \mathrm{~N}_{\text {anti-EGFR+ASA }}=5 .(\mathrm{C}$ and F) The proportion of HCT116 and HT29 cells accumulated in the $\mathrm{G}_{0} / \mathrm{G}_{1}$ phase of the cell cycle, respectively. For HCT116-derived colonospheres: $\mathrm{N}_{\mathrm{CONTROL}}=10, \mathrm{~N}_{5-\mathrm{FU}}=12, \mathrm{~N}_{\mathrm{ASA}}=12, \mathrm{~N}_{5-\mathrm{FU}+\mathrm{ASA}}=12$, $\mathrm{N}_{\text {anti-EGFR }}=8$, NantiEGFR+5-FU = 8, NantiEGFR+ASA $=8$. For HT29-derived colonospheres: $\mathrm{N}_{\text {CONTROL }}=10, \mathrm{~N}_{5-\mathrm{FU}}=12, \mathrm{~N}_{\mathrm{ASA}}=12, \mathrm{~N}_{5-\mathrm{FU}+\mathrm{ASA}}=12, \mathrm{~N}_{\text {anti-EGFR }}=6$, NantiEGFR+5-FU $=6, \mathrm{~N}_{\text {anti-EGFR+ASA }}=6$. Statistically significant differences assessed by Kruskal-Wallis test followed by Dunn's test as a post hoc procedure and Mann-Whitney test. $\mathrm{P}<0.05,{ }^{* * *} \mathrm{P}<0.005,{ }^{* * *} \mathrm{P}<0.0005$ and ${ }^{* * * * *} \mathrm{P}<0.00005$. All data presented as the means \pm SEM. 5-FU, 5-fluorouracil; ASA, aspirin; EGFR, epidermal growth factor receptor.

autophagy (38)] confirmed the progression of that process in the HT29 cell-derived spheres treated with ASA and 5-FU + ASA (data not shown).

Analysis of COX-2 activity and expression. Since a high COX-2 expression, which catalyzes the reduction of arachidonic acid to prostaglandins, accompanies a number of pathological processes, including cancer growth, we decided to examine its level in the treated colonospheres. Independently of the CRC cell line or type of drug/drugs, the cell fractions containing intracellular COX-2 did not change after $72 \mathrm{~h}$ of treatment of the spheres in the cytometrical analysis (Table I). Nevertheless, we decided also to determine the enzyme's activity in a COX activity assay which compares changes in the medium 

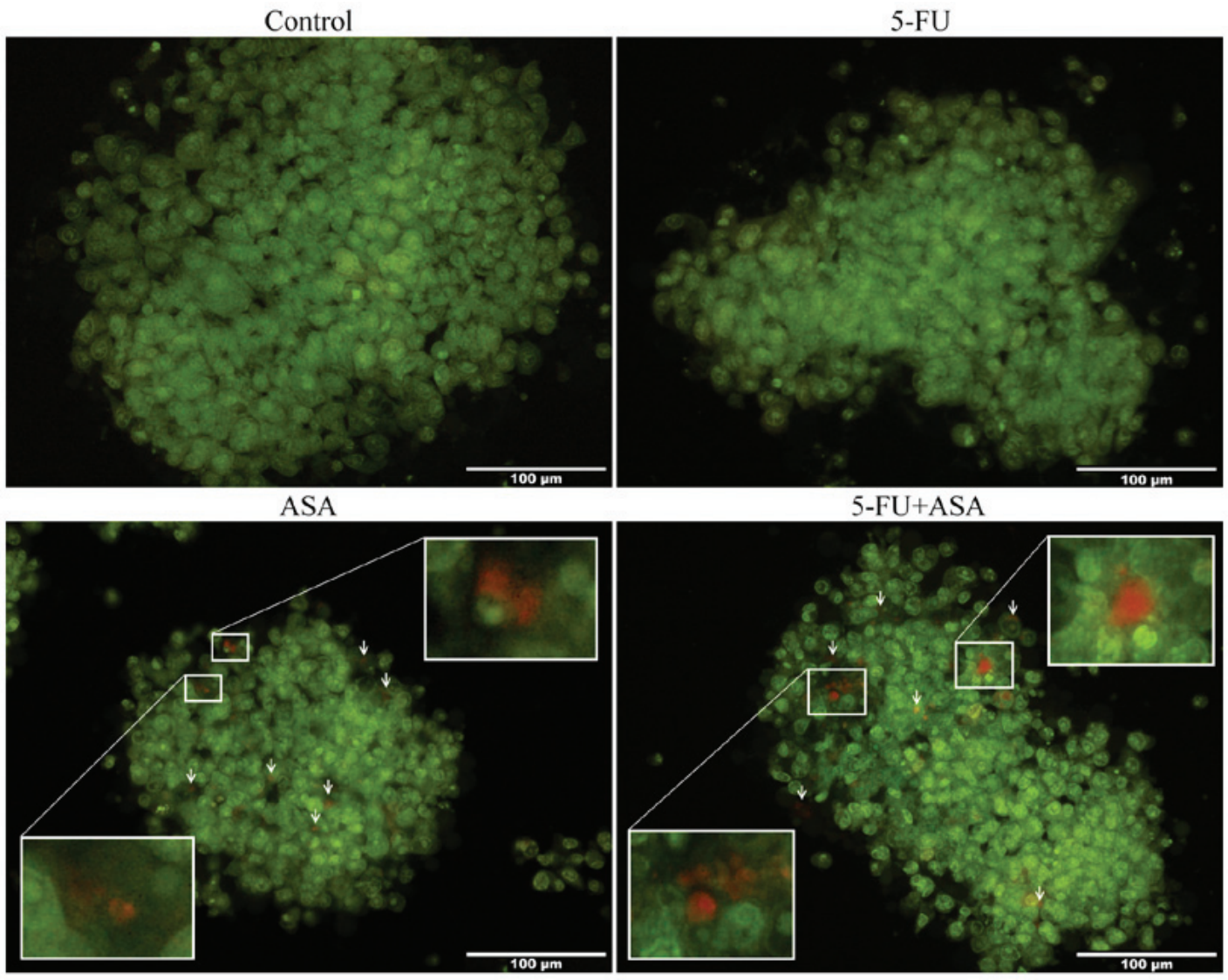

Figure 10. Detection of autophagy in HT29 cell-derived spheres treated with 5-FU, ASA and 5-FU + ASA. Confocal images of HT29 cell-derived spheres treated with 5-FU, ASA, and 5-FU + ASA for $72 \mathrm{~h}$. Cells were stained with AO and examined by confocal microscopy. Short arrows indicate acidic vacuoles (AVOs). 5-FU, 5-fluorouracil; ASA, aspirin; EGFR, epidermal growth factor receptor; AO, acridine orange.
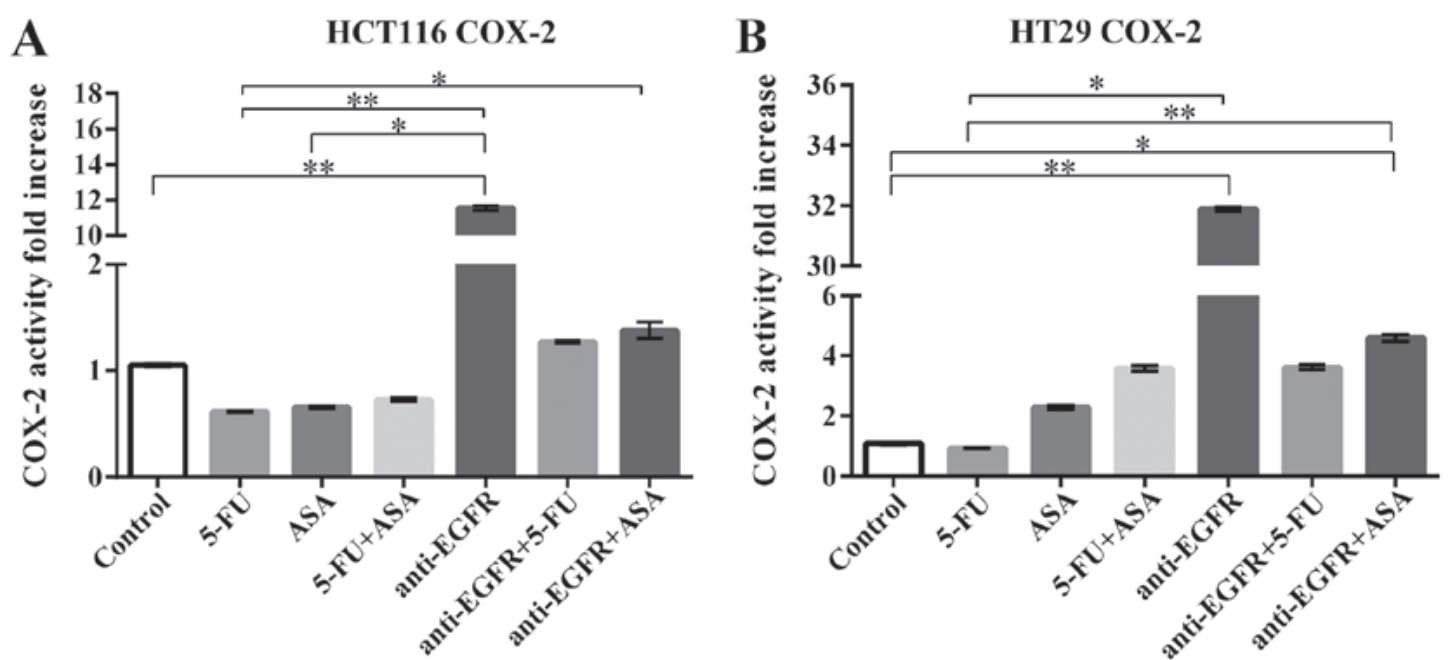

Figure 11. Assessment of COX-2 activity displayed by (A) HCT116 and (B) HT29 colonospheres following incubation of the spheres with drugs and their combinations. The activity of COX-2 was established within the protein lysate of the treated cells. Experiments were performed 3 times in duplicate. Statistically significant differences assessed by Kruskal-Wallis test followed by Dunn's test as a post hoc procedure. ${ }^{*} \mathrm{P}<0.05$ and ${ }^{* *} \mathrm{P}<0.005$. All data presented as the means \pm SEM. 5-FU, 5-fluorouracil; ASA, aspirin; EGFR, epidermal growth factor receptor; COX-2, cyclooxygenase-2.

fluorescence $(\mathrm{Ex} / \mathrm{Em}=535 / 587 \mathrm{~nm})$ caused by the conversion of a COX substrate, arachidonic acid, into prostaglandins. Incubation of the HCT116-derived colonospheres with 5-FU, ASA and 5-FU + ASA resulted in a slight, statistically insignificant decrease in COX-2 activity, whereas anti-EGFR antibody caused a 12-fold increase in COX-2 activity in comparison to the unstimulated cells (Fig. 11A). We observed that the HT29-derived colonospheres incubated with the tested drugs exhibited an increased COX-2 activity, apart from those treated with 5-FU. However, the increase was statistically significant in comparison to the control only for the anti-EGFR antibodyand anti-EGFR antibody + ASA-treated cells (Fig. 11B). 
Table I. Assessment of the COX-2-positive cells in HCT116- and HT29-colonospheres.

\begin{tabular}{lcccccc}
\hline & Control & 5-FU & ASA & 5-FU ASA & anti-EGFR & $\begin{array}{c}\text { anti-EGFR }^{+} \\
\text {5-FU }\end{array}$ \\
& & & & & & \\
anti-EGFR & ASA
\end{tabular}

The percentage of HCT116 and HT29 cells expressing COX-2 after $72 \mathrm{~h}$ of incubation with the drugs and their combinations. The experiments were performed at least 5 times. No statistical significant differences were obtained.

\section{Discussion}

$\mathrm{CRC}$ is one of the most commonly diagnosed and lethal types of cancer worldwide. Colorectal carcinogenesis is a multistep process requiring the accumulation of various genetic and epigenetic aberrations. There are two different models of carcinogenesis: The stochastic and the CSC model (39). According to the stochastic model, any type of cell is capable of initiating and promoting cancer development, whereas the CSC model is an attractive hypothesis that translates the properties of normal stem cells into the cancer field, and explains some of the most lethal features of cancer (39). CSCs are known to maintain a non-proliferative state and to enter the cell cycle only infrequently. Conventional anticancer therapies preferentially target dividing cells, whereas CSC-like cells are resistant to such treatments. Moreover, they can potentially initiate disease relapse and metastasis as they re-enter the cell cycle after a period of dormancy $(40,41)$. CSC-like cells were considered as a population with well-defined phenotypic and molecular features; however, a growing body of evidence suggests that they are a rather dynamic cellular fraction continuously shaped by the convergence of genetic, epigenetic and microenvironmental factors (42).

Solid tumors grow in a three-dimensional (3D) spatial conformation, resulting in heterogeneous exposure to oxygen and nutrients, as well as to physical and chemical stresses, which is not mirrored in the $2 \mathrm{D}$ adherent systems of cancer cell cultures (43). It has been suggested that spherical cultures better mimic the cancer cell organization and development in vivo $(10,12,44)$. Similar to solid tumors, the external layer of a sphere is composed of cells displaying high proliferation rates, the middle layer is essentially formed by senescent cells, and the core contains necrotic cells (11).

In this study, we performed a series of experiments to determine the effects of some therapeutic agents and their combinations on the features of the CSC-like cells present within the spherical cultures of two different CRC lines. We selected 5-FU, as a conventional agent in the first line of CRC treatment (20), ASA due to its potential chemopreventive role in CRC $(30,45)$, and anti-EGFR antibody, since the blockage of EGFR has been shown to be effective in some types of cancer, including CRC (28). Taken together, ASA and anti-EGFR antibodies are suggested as promising agents in the prevention or treatment of CRC, and their potential therapeutic usage may result in enhanced, synergistic anticancer effects (46). Admittedly, the morphology of the colonospheres and their sizes were significantly reduced by single-agent treatment; however, we observed that combinations of two agents had the most significant impact on the viability of CRC spheres. Pre-treatment of the CRC cells displayed that the spherical cultures were more resistant to the tested drugs what was reflected in their capability to re-create colonospheres when maintained in serum-free medium. The CRC cell lines used in this study presented a different status with respect to the expression of some genes important in CRC pathogenesis. HT29 cells express KRAS ${ }^{\mathrm{WT}}$, mutated both $\mathrm{BRAF}^{\mathrm{V} 600 \mathrm{E}}$ and p53 ${ }^{\mathrm{R} 273 \mathrm{H}}$, while HCT116 cells express mutated $\mathrm{KRAS}^{\mathrm{G} 13 \mathrm{D}}$ and non-mutated BRAF ${ }^{\mathrm{WT}}$ and $\mathrm{p} 53^{\mathrm{WT}}$ (47). Thus, these CRC cell lines presented a differential response to the selected agents. Of note, the HCT116-derived CSC-like cells were more affected by the tested drugs in comparison to the HT29-CSC-derived fraction. Furthermore, a series of experiments revealed that the tested compounds induced an increase in the frequency of non-viable cells in spherical cultures. This phenomenon seems to not depend on the reduction of cells expressing an active form of caspase-3. Hence, it indicated that different cellular pathways were involved in development of cellular death. Additionally, we demonstrated that ASA alone or in combination with 5-FU caused the progression of the autophagy process in the treated colonospheres. We hypothesized this may be related to the action mechanism of ASA, since the inhibition of COX-2 was not confirmed in the performed experiments. Notably, we also noted that the blockage of EGFR positively influenced the activity of COX-2, indicating the crosstalk between EGFR and COX-2 in the colonospheres.

First of all, the colonospheres incubated with 5-FU, ASA anti-EGFR antibody or their combinations for $72 \mathrm{~h}$ presented visible morphological changes. General morphology changes included a significant decrease in the size of the colonospheres in both lines, apart from the anti-EGFR antibody-treated HT29-derived colonospheres, thus confirming the effective concentrations of the used drugs. In agreement with our findings, other authors have also observed a decreased colonosphere diameter $(12,31,33)$. Since according to our previous study (10), not only colonospheres, but also adherent forms of HCT116 and HT29 cells contain cells with CSC-like antigens on their surface, we decided to treat the cells in monolayer with the selected drugs and then transferred them into sphere-forming conditions to assess their sphere-forming ability following such pre-treatment. However, both the parental cell lines pre-treated with the therapeutic agents were unable to build the colonospheres when cultured in SCM. Notably, ASA pre-treatment led to the aggregation of cells into larger groups in both CRC cell lines; thus, it was suggested that ASA affected 
the colonosphere-forming ability, although at the same time, ASA allowed the formation of cellular aggregates, which is in agreement with the analysis of $\mathrm{CD} 44^{+} \mathrm{CD} 29^{+}$phenotype of HCT116 cells. Subsequently, to determine the secondary sphere formation capacity, we treated the developed colonospheres with the therapeutic agents for $72 \mathrm{~h}$. The re-creation of colonospheres following such a pre-treatment was evaluated thereon. Overall, spherical cultures were less affected by the therapeutic agents than their adherent correspondents as revealed by the greater capacity to recreate colonospheres following the exposure to the tested drugs. We hypothesized that it may be related to the internal heterogeneity of cells within spheres and the presence of fraction with more primitive phenotype, such as CSC-like cells. Additionally, the lack of differences in the proliferation rate between HT29-derived colonospheres exposed to the studied agents and untreated cells confirms that colonospheres are a more stable research system than correspondent adherent cultures. Colonospheres also present a greater resistance to standard chemotherapeutic agents probably due to the occurrence of CSC-like cells within them. These remarks are in agreement with the observations of other authors $(9,12,43)$.

In our previous study, we characterized the fraction of cells within colonospheres from both studied CRC lines according to their phenotype (10). It must be stressed that there is no unique CRC CSC-like marker. In recent literature, a number of molecules have been proposed as such markers, e.g., CD44, CD24, CD26, CD29, CD166, Bmi-1, Lgr-5, ABCB5, ALDH, and the most well-known CD133 $(15,20)$. CD133 was originally used by two independent research groups to isolate and characterize the CSC-like cells for the first time $(2,3)$. Therefore, the expression of this antigen was our first choice to determine whether the studied agents may affect the fraction of CSC-like cells. Notably, in our study, the HT29-derived colonospheres seemed to be less affected than the HCT116 cell-derived spheres by all of the drugs, as they maintained the CD133-positive fraction on a constant level, apart from the combined agents 5-FU + ASA. By contrast, treatment of the HCT116-derived colonospheres reduced the percentage of CD133-positive cells. However, the decrease in the CD133-fraction was related to the evident tendency to increase the proportion of CD $44^{+} \mathrm{CD} 29^{+} \mathrm{CD} 133-$ cells following incubation with ASA, 5-FU + ASA, and anti-EGFR + ASA. CD44 and CD29 belong to integrins; therefore, we hypothesized that ASA may have strengthened junctions between cells within colonospheres in our study. This may explain why the ASA-pre-treated cells could form cell aggregates. Overall, when the amount of $\mathrm{CD} 133^{+}$cells were partially reduced following treatment with the drugs, we simultaneously observed a tendency for CD $44^{+} \mathrm{CD} 29^{+} \mathrm{CD} 133$ cell enrichment. This may suggest that CSCs in suboptimal culture condition leave the spheres, which corresponds to EMT and the invasion of CSC-like cells in vivo. As CSC-like cells do not undergo anoikis when they lose the attachment to neighboring cells or extracellular matrix elements, they may leave the sphere and survive in the serum-free medium. Thus, on the basis of the aforementioned results, it can be concluded that CSC-like cells were probably responsible for the regeneration of secondary spheres in our assay.

FasR, belonging to the tumor necrosis factor (TNF) family, is a transmembrane protein with a cytoplasmic death domain. However, studies have demonstrated the importance of the non-apoptotic role of the FasR/FasL cascade also for tumor promotion. FasR, acting as an activator of PI3K, can induce the invasion of glioblastoma cells, since its neutralization with MFL3-antibody markedly reduces the number of invading cells (48). Subsequently, the knockdown of either FasR or FasL induced by siRNA or shRNA has been shown to significantly decrease the growth of cancer cells derived from various cancer cell lines (35). Once cancer cells achieve resistance to FasR-mediated apoptosis, further stimulation of that death receptor is tumorigenic (49). Therefore, the downregulation of FasR expression is associated with cancer progression; however, its complete loss is rather infrequent; thus, FasR expression in cancer cells is suspected to represent a part of a tumor-security mechanism (35). We have previously demonstrated (36) that spherical cultures were characterized by the diminished level of FasR in comparison to their adherent counterparts, thus confirming the resemblance of the spherical system to the cancer tissue in vivo. In the present study, we observed a very low percentage of FasR-positive cells in the HT29-derived colonospheres, which further decreased following treatment with anti-EGFR antibody and its combination with 5-FU and ASA. It may be interpreted as an adaptation of the cancer cells to minimize the probability of apoptosis induction, while benefiting from tumorigenic activities. We previously found significant positive correlations between FasR and some CSC-like markers, which seemed to indicate the cancer-promoting role of FasR signaling, while FasL seemed to be involved in cancer progression rather than in CSC-like cells maintenance (36). Furthermore, the FasR/FasL of HCT116-spherical system was not markedly affected by the exposure to the tested agents. The percentage of FasL-positive cells from the HT29-derived colonospheres and HCT116-derived colonospheres was significantly reduced only by 5-FU + ASA and ASA, respectively, whereas the other agents had no marked effect on the high fraction of FasL-positive cells. Therefore, we propose that ASA or its combinations may present a useful tool with which to reduce the FasL level.

The incubation of colonospheres with the tested agents resulted in a decreased viability; however, the percentage of non-living cells was markedly higher in the adherent models in comparison to their spherical counterparts (data not shown), thus confirming that spheres are more resistant platform to the therapeutic agents. In our previous study (10), we demonstrated that spherical CRC cultures contained a prominent percentage of non-living cells, but still presented a very stable population with a fraction of cells continuously proliferating. As was expected, the combination of two agents, such as 5-FU + ASA, anti-EGFR antibody + 5-FU, or anti-EGFR antibody + ASA, significantly increased the amount of non-viable cells in both CRC cell lines, whereas single agents were inefficient in that manner. These data are partially in agreement with our data on the proliferation and accumulation of cells in $G_{0} / G_{1}$ phase of the cell cycle. In brief, although the proportion of dividing cells following incubation with ASA alone increased significantly, the general proliferation rate of the HCT116 cells was not affected. We observed that the simultaneous administration of ASA with 5-FU or anti-EGFR antibody decreased the number of spherical HCT116 proliferating cells. This decrease may be associated with the ability of these drug combinations 
to target cells in their active phases of the cell cycle, since the percentage of cells in $\mathrm{G}_{0} / \mathrm{G}_{1}$ phase was reduced. Basing on the presented results, we suggest that HCT116-derived colonosphere exposition to ASA diminishes the amount of quiescent cells and induces their transformation into extensively dividing cells, which could be easier eliminated by $5-\mathrm{FU}$ or anti-EGFR antibody. By contrast, HT29 cell proliferation and the number of cells in the $G_{0} / G_{1}$ phase were affected by ASA, alone whereas combined treatment with 5-FU or anti-EGFR antibody was not effective.

Of note, we obtained similar viability results for both the anti-EGFR antibody-treated CRC cell lines, in spite of the fact that HT29 and HCT116 cell lines represent a different KRAS gene status, which is wild-type and G13D-mutated, respectively (47). According to other studies, the susceptibility of cancer cell lines to anti-EGFR antibody stimulation depends on a number of different factors, and the genetic status of the KRAS gene is not the only feature that may influence the cells' behavior (50-52). Moreover, despite a positive response to the treatment with anti-EGFR antibodies, a number of patients with CRC develop resistance to such EGFR blockade, which may be driven by the emergence of KRAS mutations or by the development of EGFR extracellular domain variants, which impair antibody binding $(29,53)$. Hence, patients with mutations within codon 12 or 13 should be excluded from the anti-EGFR therapeutic regiments as they would not gain any benefits from such a therapy (54). However, recent studies presented contrary results, suggesting that a therapeutic effect may be obtained even in patients harboring the KRAS G13D mutation $(55,56)$. Furthermore, our in vitro results revealed that 5-FU treatment with the simultaneous blockage of EGFR in both CRC lines decreased the percentage of living cells in colonospheres and in cells cultured in their adherent mode (data not shown). However, the NORDIC-VII in vivo study reported no effect of adding cetuximab, which is a chimeric monoclonal antibody inhibiting EGFR, to a regimen of bolus 5-FU/folinic acid (FA) and oxaliplatin in the first-line therapy of metastatic CRC (57). Furthermore, Guren et al demonstrated an effect of cetuximab monotherapy in patients with RAS/BRAF wild-type tumors (58), while the COIN trial demonstrated a lack of effect when adding cetuximab to an oxaliplatin-capecitabine regimen in KRAS wild-type cases (59). This study demonstrated that EGFR blockage exerts a significant impact on many features of the colonospheres independently of their KRAS status. We hypothesized that the positive outcome of anti-EGFR treatment is related to the general mutational gene status of cells. For instance, the HCT116 cell line harbors mutated KRAS ${ }^{\mathrm{G} 13 \mathrm{D}}$, but it expresses the non-mutated wild-type of two crucial death-associated genes, BRAF and p53. Thus, their non-affected status may partially explain the significant response to EGFR blockage. Still, the discrepancies amongst the results require further investigations, since EGFR and its ligand are implicated in a number of signaling pathways.

The development and progression of a number of types of cancer, including CRC, and the existence of pre-malignant tissues has been reported to be commonly accompanied by the overexpression of the COX-2 gene (60), which is usually associated with a poor prognosis of cancer patients (61-63). However, it has to be stressed that these data strongly vary and seem to depend on the used methodology $(60,61)$. In fact, western blot analyses of COX-2 protein have indicated its expression in the HT29 cell line $(61,64)$, whereas HCT116 lacks that particular protein $(61,65)$. In this study, we established that COX $-2^{+}$spherical HT29 and HCT116 cells comprised 15.5 and $13.3 \%$ of the total cell population respectively, and these numbers were mostly unaffected by treatment with the tested agents. Subsequently, we decided to test the activity of the COX-2, since ASA is known as an irreversible and nonselective inhibitor of that enzyme (66). It must be stressed that none of the agents inhibited COX-2 activity in the HT29- or HCT116-derived colonospheres. Surprisingly, although ASA is considered to act as a COX-2 inhibitor, in this study, it did not suppress COX-2 activity. This may be due to the used $1.5 \mathrm{mM}$ concentration, while other researchers used varying concentrations ranging up to $10 \mathrm{mM}$. Some researchers have suggested that ASA can act through COX-independent mechanisms to exert an anti-neoplastic effect $(30,66)$. Notably, the anti-EGFR antibody-treated HCT116-derived colonospheres, as well as the anti-EGFR antibody- and anti-EGFR antibody + ASA-treated HT29-derived colonospheres, presented an elevated COX-2 activity. We hypothesized that COX-2 expression may be stimulated by other factors. Furthermore, in both the studied CRC spherical lines, anti-EGFR antibody increased COX-2 activity. The significance of crosstalk between EGFR and COX-2 in carcinogenesis has been shown in previous independent studies on different types of cancer, including CRC (67,68). Notably, the COX-2 and EGFR pathways mutually enhance their pro-tumorigenic effects in a number of types of cancer (69-71) through the stimulation of their effectors, such as EGFR-ligand, AKT, ERK and MAPK (70,72).

Furthermore, to establish the type of cell death resulting from a treatment, we decided to assess the percentage of cells exhibiting the active form of caspase-3, which is known as an executioner type of a cysteine-aspartic protease involved in the apoptotic process. Surprisingly, its level was significantly reduced in the colonospheres derived from the HT29 CRC cell line treated with anti-EGFR antibody and ASA, but not 5-FU, whereas its expression in the HCT116-derived colonospheres was only slightly affected by the tested drugs. It is widely known that caspases may act as mediators in different types of cell death, such as apoptosis, pyroptosis and necroptosis. However, is has to be stressed that their function is not limited to the regulation of cell death mechanisms (73). A deficiency in caspase-3 expression has been shown to affect the differentiation of embryonic and hematopoietic stem cells due to a cleavage of Nanog and the maintenance of a dormant state of stem cells $(74,75)$. Of note, Flanagan et al revealed that a subgroup of CRC patients with low levels of active form of caspase-3 was characterized by an increased disease-free survival (76). In line with our findings, a study conducted on CRC-patient-derived primary tumor explant cultures revealed that ASA did not affect caspase-3 activation and apoptosis induction (76). According to the results of this study, ASA did not trigger the typical apoptotic process with caspase-3 activation, but induced only a slight tendency in the increase of the necrotic cell percentage. Notably, despite the decreased caspase-3 level in the HT29-derived colonospheres treated with anti-EGFR antibody and its combination with 5-FU and ASA, we found an increased percentage of apoptotic cells and a reduced amount of necrotic cells within the culture. This 
indicated that the apoptosis-associated changes in colonospheres were not caspase-3-related, since the execution of cell death may occur in a caspase-dependent manner even in cells with reduced levels or devoid of caspase-3. It has been shown that other executioner caspases, e.g., caspase- 6 or caspase-7, may in part substitute for the diminished or lacking caspase-3 activity (77). Additionally, this phenomenon may be triggered by alternative and compensatory signaling cascades involving other proteases, such as serine proteases, cathepsins and calpains (77). Moreover, Huang et al in multiple in vitro and in vivo experiments, proved that dying breast cancer cells influenced the remaining cancer cell population to replenish the cancer bulk via the caspase-3 stimulation which in turn may induce the growth of surviving tumor cells by paracrine mode (78). They showed that wild-type and $\mathrm{Casp}^{-/-}$mouse embryonic fibroblasts presented a similarly decreased survival after irradiation, thus indicating that the absence of caspase- 3 shifts the mode of cell death from apoptosis to necrosis or autophagy (78). Of note, the activation of a pathway downstream of caspase-3 results in the increased secretion of prostaglandin 2 (PGE2) $(78,79)$, which then stimulates stem cell proliferation, tissue regeneration and repair (79). This can explain why the HCT116 cells in our cultures exhibited a decreased CD $133^{+}$CSC-like cell number, particularly following anti-EGFR antibody stimulation when we found a much lower caspase-3 level.

The next step of this study was to assess the change of the inner mitochondrial membrane potential, which is not only a hallmark of apoptosis, but also influences stem cell viability, proliferation, differentiation and their lifespan (80). An increased mitochondrial membrane potential $(\Delta \psi \mathrm{m})$ is found in many tumors, and alterations in mitochondrial function are hallmarks of neoplastic transformation of colonic epithelial cells (81). Heerdt et al created 5 isogenic SW620 CRC cell lines using mitochondria-targeted agents which differed according to the $\Delta \psi \mathrm{m}$. Their detailed analyses revealed that $\Delta \psi \mathrm{m}$ was not necessarily related to the alterations in cell viability in culture. In this study, we observed that following treatment with the drugs, the percentage of intensively stained cells with highly polarized mitochondrial membranes increased in the HCT116 spherical cultures, whereas the HT29 cell-derived spheres exhibited a reduced percentage of these cells. A series of studies have confirmed that cells with an elevated intrinsic $\Delta \psi \mathrm{m}$ are characterized by higher resistance to apoptotic inducers and hypoxia, increased invasive behavior, a greater ability to escape from anoikis, and growth under anchorage-independent conditions, in comparison to the parental cell lines or cells with decreased $\Delta \psi \mathrm{m}$ (81-83). Thus, mitochondrial $\Delta \psi \mathrm{m}$ changes play a role in carcinogenesis, including tumor development, expansion and progression. Accordingly, Ye et al postulated that a higher $\Delta \psi \mathrm{m}$ may be used to isolate lung cancer stem cells, since these cells exhibited also CD133 antigen (84). In vivo analyses of patient-derived glioblastoma multiforme tissues and ovarian cancer have demonstrated that CSCs possess higher $\Delta \psi \mathrm{m}$ than the neighboring non-CSCs $(85,86)$. These data suggest that differences in the intrinsic $\Delta \psi \mathrm{m}$ of cancer cells are likely to be associated with subtle shifts in the biochemical pathways and/or cell phenotypes that play fundamental roles in determining the probability of tumorigenesis. The results of this study demonstrating a decrease in the population of cells with the highest $\Delta \psi \mathrm{m}$ within the spherical
HT29 cell line could be associated with increased apoptosis, necrosis, and a lower proliferation rate of these cells, which seems to confirm the hypothesis that cells with an elevated mitochondrial membrane potential are responsible for tumor progression. However, spheres following treatment with the tested agents, the HCT116 cell-derived presented an increased percentage of cells with a higher $\Delta \psi \mathrm{m}$, thus confirming the general hypothesis that chemotherapy can increase the fraction of cells with CSC-like features.

Since the low level or absence of caspase-3 can trigger the mode shift from apoptosis to necrosis or autophagy, we decided to analyze the progression of autophagy. Treatment of the HT29-derived colonospheres, but not the HCT116-derived colonospheres, with ASA and 5-FU + ASA led to the progression of autophagy, assessed by the immunofluorescence staining with AO. The ability of ASA to induce autophagy has been reported in studies which have suggested that ASA can impair the mTOR signaling cascade due to the inhibition of mTOR effectors, S6K1 and 4E-BP1, or AMPK-mediated ULK1 phosphorylation $(23,87)$. Under physiological conditions, mTOR prevents the progression of autophagy by maintaining the hyperphosphorylation of proteins required for the initiation of the autophagic cascade (88).

To summarize, in this study, we examined the effects of drugs targeting different processes and signaling pathways within a heterogeneous cancer cell population enriched within CSC-like cells present in colonospheres derived from two widely studied CRC cell lines. We suggest that the difference in the susceptibility of cells to the tested agents may be caused by their different differentiation status. Since HCT116 cells represent a non-differentiated and highly aggressive cell line corresponding to the TNM III stage, we hypothesized that the fraction of highly resistant cancer stem-like cells should be higher than in HT29 cells, which are known as less invasive (corresponding to the TNM II). Our study further confirms that the cancer cell spherical culture systems (rather than adherent cell cultures) should be used for the in vitro testing of anticancer therapeutics, since functional tests confirmed the presence of cells harboring CSC-like features within 3D models of CRC. Our results confirm that the use of a single (potentially) anticancer agent affects mostly the cells constituting the major tumor mass, which can be easily rebuilt by the activation of cells with CSC-properties (89). Ambiguous results concerning both analyzed CRC cell lines suggest that the three tested drugs act on various cellular processes and signaling pathways, and therefore should be considered for the combined therapeutic treatment of CRC. Moreover, the results of our investigations clearly demonstrate that cancer cell spheres should be used as a preferable model for in vitro anticancer drug testing, particularly those targeting CSCs responsible for the most serious therapeutic limitations.

\section{Acknowledgements}

Not applicable.

\section{Funding}

This study was supported by the grant from the Polish Ministry of Science and Higher Education no. MN 01-0232/08/280. 


\section{Availability of data and materials}

The datasets used and/or analyzed during the current study are available from the corresponding author on reasonable request.

\section{Authors' contributions}

AOK was responsible for planning and conducting the experiments, analyzing the results and writing and reviewing the manuscript. MS was involved in planning the experiments, analyzing the results and editing the manuscript. AW and KSK were involved in performing the autophagy experiments and editing the manuscript. ZK was involved in the conception and the planning of the experiments and editing the manuscript. All authors have read and approved the final manuscript.

\section{Ethics approval and consent to participate}

Not applicable.

\section{Patient consent for publication}

Not applicable.

\section{Competing interests}

The authors declare that they have no competing interests.

\section{References}

1. Arnold M, Sierra MS, Laversanne M, Soerjomataram I, Jemal A and Bray F: Global patterns and trends in colorectal cancer incidence and mortality. Gut 66: 683-691, 2017.

2. Ricci-Vitiani L, Lombardi DG, Pilozzi E, Biffoni M, Todaro M, Peschle C and De Maria R: Identification and expansion of human colon-cancer-initiating cells. Nature 445: 111-115, 2007.

3. O'Brien CA, Pollett A, Gallinger S and Dick JE: A human colon cancer cell capable of initiating tumour growth in immunodeficient mice. Nature 445: 106-110, 2007.

4. Chen X, Liao R, Li D and Sun J: Induced cancer stem cells generated by radiochemotherapy and their therapeutic implications. Oncotarget 8: 17301-17312, 2017.

5. Wang SS, Jiang J, Liang XH and Tang YL: Links between cancer stem cells and epithelial-mesenchymal transition. Onco Targets Ther 8: 2973-2980, 2015.

6. Celià-Terrassa $\mathrm{T}$ and Kang Y: Distinctive properties of metastasis-initiating cells. Genes Dev 30: 892-908, 2016.

7. Hutchinson L and Kirk R: High drug attrition rates--where are we going wrong? Nat Rev Clin Oncol 8: 189-190, 2011.

8. Sant S and Johnston PA: The production of 3D tumor spheroids for cancer drug discovery. Drug Discov Today Technol 23: 27-36, 2017.

9. Karlsson H, Fryknäs M, Larsson R and Nygren P: Loss of cancer drug activity in colon cancer HCT-116 cells during spheroid formation in a new 3-D spheroid cell culture system. Exp Cell Res 318: 1577-1585, 2012.

10. Olejniczak A, Szaryńska M and Kmieć Z: In vitro characterization of spheres derived from colorectal cancer cell lines. Int J Oncol 52: 599-612, 2018.

11. Costa EC, Moreira AF, de Melo-Diogo D, Gaspar VM, Carvalho MP and Correia IJ: 3D tumor spheroids: An overview on the tools and techniques used for their analysis. Biotechnol Adv 34: 1427-1441, 2016.

12. Qureshi-Baig K, Ullmann P, Rodriguez F, Frasquilho S, Nazarov PV, Haan S and Letellier E: What do we learn from spheroid culture systems? Insights from tumorspheres derived from primary colon cancer tissue. PLoS One 11: e0146052, 2016.

13. Kim SY, Hong SH, Basse PH, Wu C, Bartlett DL, Kwon YT and Lee YJ: Cancer stem cells protect non-stem cells from anoikis: Bystander effects. J Cell Biochem 117: 2289-2301, 2016.
14. Paoli P, Giannoni E and Chiarugi P: Anoikis molecular pathways and its role in cancer progression. Biochim Biophys Acta 1833: 3481-3498, 2013.

15. Islam F, Gopalan V, Smith RA and Lam AK: Translational potential of cancer stem cells: A review of the detection of cancer stem cells and their roles in cancer recurrence and cancer treatment. Exp Cell Res 335: 135-147, 2015.

16. Siddique HR and Saleem M: Role of BMI1, a stem cell factor, in cancer recurrence and chemoresistance: Preclinical and clinical evidences. Stem Cells 30: 372-378, 2012.

17. Yan KS, Chia LA, Li X, Ootani A, Su J, Lee JY, Su N, Luo Y, Heilshorn SC, Amieva MR, et al: The intestinal stem cell markers Bmil and Lgr5 identify two functionally distinct populations. Proc Natl Acad Sci USA 109: 466-471, 2012.

18. Manhas J, Bhattacharya A, Agrawal SK, Gupta B, Das P, Deo SV, Pal S and Sen S: Characterization of cancer stem cells from different grades of human colorectal cancer. Tumour Biol 37: 14069-14081, 2016.

19. Butler SJ, Richardson L, Farias N, Morrison J and Coomber BL: Characterization of cancer stem cell drug resistance in the human colorectal cancer cell lines HCT116 and SW480. Biochem Biophys Res Commun 490: 29-35, 2017.

20. Szaryńska M, Olejniczak A, Kobiela J, Spychalski P and Kmieć Z: Therapeutic strategies against cancer stem cells in human colorectal cancer. Oncol Lett 14: 7653-7668, 2017.

21. Chan AT, Manson JE, Feskanich D, Stampfer MJ, Colditz GA and Fuchs CS: Long-term aspirin use and mortality in women. Arch Intern Med 167: 562-572, 2007.

22. Thorat MA and Cuzick J: Role of aspirin in cancer prevention. Curr Oncol Rep 15: 533-540, 2013.

23. Din FV, Valanciute A, Houde VP, Zibrova D, Green KA, Sakamoto K, Alessi DR and Dunlop MG: Aspirin inhibits mTOR signaling, activates AMP-activated protein kinase, and induces autophagy in colorectal cancer cells. Gastroenterology 142: 1504-1515 e1503, 2012.

24. Kaur J and Sanyal SN: PI3-kinase/Wnt association mediates COX-2/PGE(2) pathway to inhibit apoptosis in early stages of colon carcinogenesis: Chemoprevention by diclofenac. Tumour Biol 31: 623-631, 2010.

25. Saha S, Mukherjee S, Khan P, Kajal K, Mazumdar M, Manna A, Mukherjee S, De S, Jana D, Sarkar DK, et al: Aspirin suppresses the acquisition of chemoresistance in breast cancer by disrupting an NFkappaB-IL6 signaling axis responsible for the generation of cancer stem cells. Cancer Res 76: 2000-2012, 2016.

26. Kastrati I, Litosh VA, Zhao S, Alvarez M, Thatcher GR and Frasor J: A novel aspirin prodrug inhibits NFKB activity and breast cancer stem cell properties. BMC Cancer 15: 845, 2015.

27. Moon CM, Kwon JH, Kim JS, Oh SH, Jin Lee K, Park JJ, Pil Hong S, Cheon JH, Kim TI and Kim WH: Nonsteroidal anti-inflammatory drugs suppress cancer stem cells via inhibiting PTGS2 (cyclooxygenase 2) and NOTCH/HES1 and activating PPARG in colorectal cancer. Int J Cancer 134: 519-529, 2014.

28. Miyamoto Y, Suyama K and Baba H: Recent advances in targeting the EGFR signaling pathway for the treatment of metastatic colorectal cancer. Int J Mol Sci 18: 18, 2017.

29. Van Emburgh BO, Sartore-Bianchi A, Di Nicolantonio F, Siena S and Bardelli A: Acquired resistance to EGFR-targeted therapies in colorectal cancer. Mol Oncol 8: 1084-1094, 2014.

30. Goel A, Chang DK, Ricciardiello L, Gasche C and Boland CR: A novel mechanism for aspirin-mediated growth inhibition of human colon cancer cells. Clin Cancer Res 9: 383-390, 2003.

31. Wang H, Liu B, Wang J, Li J, Gong Y, Li S, Wang C, Cui B, Xue X, Yang M, et al: Reduction of NANOG mediates the inhibitory effect of aspirin on tumor growth and stemness in colorectal cancer. Cell Physiol Biochem 44: 1051-1063, 2017.

32. Mhaidat NM, Bouklihacene $M$ and Thorne RF: 5-Fluorouracil-induced apoptosis in colorectal cancer cells is caspase-9-dependent and mediated by activation of protein kinase C- $\delta$. Oncol Lett 8: 699-704, 2014.

33. Virgone-Carlotta A, Lemasson M, Mertani HC, Diaz JJ, Monnier S, Dehoux T, Delanoë-Ayari H, Rivière C and Rieu JP: In-depth phenotypic characterization of multicellular tumor spheroids: Effects of 5-Fluorouracil. PLoS One 12: e0188100, 2017.

34. Martin-Villalba A, Llorens-Bobadilla E and Wollny D: CD95 in cancer: Tool or target? Trends Mol Med 19: 329-335, 2013.

35. Chen L, Park SM, Tumanov AV, Hau A, Sawada K, Feig C, Turner JR, Fu YX, Romero IL, Lengyel E, et al: CD95 promotes tumour growth. Nature 465: 492-496, 2010. 
36. Szarynska M, Olejniczak A, Wierzbicki P, Kobiela J, Laski D, Sledzinski Z, Adrych K, Guzek M and Kmiec Z: FasR and FasL in colorectal cancer. Int J Oncol 51: 975-986, 2017.

37. Ceppi P, Hadji A, Kohlhapp FJ, Pattanayak A, Hau A, Liu X, Liu H, Murmann AE and Peter ME: CD95 and CD95L promote and protect cancer stem cells. Nat Commun 5: 5238, 2014.

38. Mancias JD and Kimmelman AC: Mechanisms of selective autophagy in normal physiology and cancer. J Mol Biol 428 : $1659-1680,2016$

39. Vaiopoulos AG, Kostakis ID, Koutsilieris M and Papavassiliou AG: Colorectal cancer stem cells. Stem Cells 30: 363-371, 2012.

40. Gao XL, Zhang M, Tang YL and Liang XH: Cancer cell dormancy: Mechanisms and implications of cancer recurrence and metastasis. OncoTargets Ther 10: 5219-5228, 2017.

41. Takeishi S and Nakayama KI: To wake up cancer stem cells, or to let them sleep, that is the question. Cancer Sci 107: 875-881, 2016.

42. Kreso A and Dick JE: Evolution of the cancer stem cell model. Cell Stem Cell 14: 275-291, 2014.

43. Weiswald LB, Bellet D and Dangles-Marie V: Spherical cancer models in tumor biology. Neoplasia 17: 1-15, 2015.

44. Szaryńska M, Olejniczak A, Kobiela J, Łaski D, Śledziński Z and Kmieć Z: Cancer stem cells as targets for DC-based immunotherapy of colorectal cancer. Sci Rep 8: 12042, 2018.

45. Drew DA, Cao Y and Chan AT: Aspirin and colorectal cancer: The promise of precision chemoprevention. Nat Rev Cancer 16 173-186, 2016

46. Valverde A, Peñarando J, Cañas A, López-Sánchez LM, Conde F, Guil-Luna S, Hernández V, Villar C, Morales-Estévez C, de la Haba-Rodríguez J, et al: The addition of celecoxib improves the antitumor effect of cetuximab in colorectal cancer: Role of EGFR-RAS-FOXM1- $\beta$ - catenin signaling axis. Oncotarget 8 : 21754-21769, 2017.

47. Ahmed D, Eide PW, Eilertsen IA, Danielsen SA, Eknæs M, Hektoen M, Lind GE and Lothe RA: Epigenetic and genetic features of 24 colon cancer cell lines. Oncogenesis 2: e71, 2013.

48. Kleber S, Sancho-Martinez I, Wiestler B, Beisel A, Gieffers C, Hill O, Thiemann M, Mueller W, Sykora J, Kuhn A, et al: Yes and PI3K bind CD95 to signal invasion of glioblastoma. Cancer Cell 13: 235-248, 2008

49. Peter ME, Hadji A, Murmann AE, Brockway S, Putzbach W, Pattanayak A and Ceppi P: The role of CD95 and CD95 ligand in cancer. Cell Death Differ 22: 885-886, 2015.

50. De Roock W, Claes B, Bernasconi D, De Schutter J, Biesmans B, Fountzilas G, Kalogeras KT, Kotoula V, Papamichael D, Laurent-Puig P, et al: Effects of KRAS, BRAF, NRAS, and PIK3CA mutations on the efficacy of cetuximab plus chemotherapy in chemotherapy-refractory metastatic colorectal cancer: A retrospective consortium analysis. Lancet Oncol 11: 753-762, 2010.

51. Karapetis CS, Khambata-Ford S, Jonker DJ, O'Callaghan CJ, Tu D, Tebbutt NC, Simes RJ, Chalchal H, Shapiro JD, Robitaille $\mathrm{S}$, et al: K-ras mutations and benefit from cetuximab in advanced colorectal cancer. N Engl J Med 359: 1757-1765, 2008.

52. Gajate P, Sastre J, Bando I, Alonso T, Cillero L, Sanz J, Caldés T and Díaz-Rubio E: Influence of KRAS p.G13D mutation in patients with metastatic colorectal cancer treated with cetuximab. Clin Colorectal Cancer 11: 291-296, 2012.

53. Misale S, Di Nicolantonio F, Sartore-Bianchi A, Siena S and Bardelli A: Resistance to anti-EGFR therapy in colorectal cancer: From heterogeneity to convergent evolution. Cancer Discov 4: 1269-1280, 2014

54. Allegra CJ, Jessup JM, Somerfield MR, Hamilton SR, Hammond EH, Hayes DF, McAllister PK, Morton RF and Schilsky RL: American Society of Clinical Oncology provisional clinical opinion: Testing for KRAS gene mutations in patients with metastatic colorectal carcinoma to predict response to anti-epidermal growth factor receptor monoclonal antibody therapy. J Clin Oncol 27: 2091-2096, 2009.

55. De Roock W, Jonker DJ, Di Nicolantonio F, Sartore-Bianchi A, Tu D, Siena S, Lamba S, Arena S, Frattini M, Piessevaux H, et al: Association of KRAS p.G13D mutation with outcome in patients with chemotherapy-refractory metastatic colorectal cancer treated with cetuximab. JAMA 304: 1812-1820, 2010

56. Tejpar S, Celik I, Schlichting M, Sartorius U, Bokemeyer C and Van Cutsem E: Association of KRAS G13D tumor mutations with outcome in patients with metastatic colorectal cancer treated with first-line chemotherapy with or without cetuximab. J Clin Oncol 30: 3570-3577, 2012
57. Tveit KM, Guren T, Glimelius B, Pfeiffer P, Sorbye H, Pyrhonen S, Sigurdsson F, Kure E, Ikdahl T, Skovlund E, et al: Phase III trial of cetuximab with continuous or intermittent fluorouracil, leucovorin, and oxaliplatin (Nordic FLOX) versus FLOX alone in first-line treatment of metastatic colorectal cancer: The NORDIC-VII study. J Clin Oncol 30: 1755-1762, 2012.

58. Guren TK,Thomsen M,KureEH,Sorbye H, Glimelius B,PfeifferP, Österlund P, Sigurdsson F, Lothe IM, Dalsgaard AM, et al: Cetuximab in treatment of metastatic colorectal cancer: Final survival analyses and extended RAS data from the NORDIC-VII study. Br J Cancer 116: 1271-1278, 2017.

59. Maughan TS, Adams RA, Smith CG, Meade AM, Seymour MT, Wilson RH, Idziaszczyk S, Harris R, Fisher D, Kenny SL, et al; MRC COIN Trial Investigators: Addition of cetuximab to oxaliplatin-based first-line combination chemotherapy for treatment of advanced colorectal cancer: Results of the randomised phase 3 MRC COIN trial. Lancet 377: 2103-2114, 2011.

60. Roelofs HM, Te Morsche RH, van Heumen BW, Nagengast FM and Peters WH: Over-expression of COX-2 mRNA in colorectal cancer. BMC Gastroenterol 14: 1, 2014.

61. Lin PC, Lin YJ, Lee CT, Liu HS and Lee JC: Cyclooxygenase-2 expression in the tumor environment is associated with poor prognosis in colorectal cancer patients. Oncol Lett 6: 733-739, 2013

62. Xu F, Li M, Zhang C, Cui J, Liu J, Li J and Jiang $\mathrm{H}$ : Clinicopathological and prognostic significance of COX-2 immunohistochemical expression in breast cancer: A meta-analysis. Oncotarget 8: 6003-6012, 2017

63. Wang ZM, Liu J, Liu HB, Ye M, Zhang YF and Yang DS Abnormal COX2 protein expression may be correlated with poor prognosis in oral cancer: A meta-analysis. BioMed Res Int 2014: 364207, 2014

64. Elder DJ, Halton DE, Crew TE and Paraskeva C: Apoptosis induction and cyclooxygenase-2 regulation in human colorecta adenoma and carcinoma cell lines by the cyclooxygenase-2-selective non-steroidal anti-inflammatory drug NS-398. Int J Cancer 86: $553-560,2000$.

65. Xu XT, Hu WT, Zhou JY and Tu Y: Celecoxib enhances the radiosensitivity of HCT116 cells in a COX-2 independent manner by up-regulating BCCIP. Am J Transl Res 9: 1088-1100, 2017.

66. Alfonso L, Ai G, Spitale RC and Bhat GJ: Molecular targets of aspirin and cancer prevention. Br J Cancer 111: 61-67, 2014.

67. Cao S, Yan Y, Zhang X, Zhang K, Liu C, Zhao G, Han J, Dong Q, Shen B, Wu A, et al: EGF stimulates cyclooxygenase-2 expression through the STAT5 signaling pathway in human lung adenocarcinoma A549 cells. Int J Oncol 39: 383-391, 2011.

68. Lippman SM, Gibson N, Subbaramaiah K and Dannenberg AJ: Combined targeting of the epidermal growth factor receptor and cyclooxygenase-2 pathways. Clin Cancer Res 11: 6097-6099, 2005.

69. Choe MS, Zhang X, Shin HJ, Shin DM and Chen ZG: Interaction between epidermal growth factor receptor- and cyclooxygenase 2-mediated pathways and its implications for the chemoprevention of head and neck cancer. Mol Cancer Ther 4: 1448-1455, 2005.

70. Huang CY and Yu LC: Pathophysiological mechanisms of death resistance in colorectal carcinoma. World J Gastroenterol 21 11777-11792, 2015

71. Kim YM, Park SY and Pyo H: Cyclooxygenase-2 (COX-2) negatively regulates expression of epidermal growth factor receptor and causes resistance to gefitinib in COX-2-overexpressing cancer cells. Mol Cancer Res 7: 1367-1377, 2009.

72. Hu H, Han T, Zhuo M, Wu LL, Yuan C, Wu L, Lei W, Jiao F and Wang LW: Elevated COX-2 expression promotes angiogenesis through EGFR/p38-MAPK/Sp1-dependent signalling in pancreatic cancer. Sci Rep 7: 470, 2017.

73. Shalini S, Dorstyn L, Dawar S and Kumar S: Old, new and emerging functions of caspases. Cell Death Differ 22: 526-539, 2015.

74. Fujita J, Crane AM, Souza MK, Dejosez M, Kyba M, Flavell RA, Thomson JA and Zwaka TP: Caspase activity mediates the differentiation of embryonic stem cells. Cell Stem Cell 2: 595-601, 2008

75. Janzen V, Fleming HE, Riedt T, Karlsson G, Riese MJ, Lo Celso C, Reynolds G, Milne CD, Paige CJ, Karlsson S, et al: Hematopoietic stem cell responsiveness to exogenous signals is limited by caspase-3. Cell Stem Cell 2: 584-594, 2008

76. Flanagan L, Meyer M, Fay J, Curry S, Bacon O, Duessmann H, John K, Boland KC, McNamara DA, Kay EW, et al: Low levels of Caspase-3 predict favourable response to 5FU-based chemotherapy in advanced colorectal cancer: Caspase-3 inhibition as a therapeutic approach. Cell Death Dis 7: e2087, 2016. 
77. Liang Y, Yan C and Schor NF: Apoptosis in the absence of caspase 3. Oncogene 20: 6570-6578, 2001.

78. Huang Q, Li F, Liu X, Li W, Shi W, Liu FF, O'Sullivan B, He Z, Peng Y, Tan AC, et al: Caspase 3-mediated stimulation of tumor cell repopulation during cancer radiotherapy. Nat Med 17: 860-866, 2011.

79. Li F, Huang Q, Chen J, Peng Y, Roop DR, Bedford JS and Li CY: Apoptotic cells activate the 'phoenix rising' pathway to promote wound healing and tissue regeneration. Sci Signal 3: ra13, 2010.

80. Pietilä M, Lehtonen S, Närhi M, Hassinen IE, Leskelä HV, Aranko K, Nordström K, Vepsäläinen A and Lehenkari P: Mitochondrial function determines the viability and osteogenic potency of human mesenchymal stem cells. Tissue Eng Part C Methods 16: 435-445, 2010.

81. Heerdt BG, Houston MA, Wilson AJ and Augenlicht LH: The intrinsic mitochondrial membrane potential (Deltapsim) is associated with steady-state mitochondrial activity and the extent to which colonic epithelial cells undergo butyrate-mediated growth arrest and apoptosis. Cancer Res 63: 6311-6319, 2003.

82. Heerdt BG, Houston MA and Augenlicht LH: The intrinsic mitochondrial membrane potential of colonic carcinoma cells is linked to the probability of tumor progression. Cancer Res 65: 9861-9867, 2005.

83. Heerdt BG, Houston MA and Augenlicht LH: Growth properties of colonic tumor cells are a function of the intrinsic mitochondrial membrane potential. Cancer Res 66: 1591-1596, 2006.
84. Ye XQ, Li Q, Wang GH, Sun FF, Huang GJ, Bian XW, Yu SC and Qian GS: Mitochondrial and energy metabolism-related properties as novel indicators of lung cancer stem cells. Int J Cancer 129: 820-831, 2011.

85. Michelakis ED, Sutendra G, Dromparis P, Webster L, Haromy A, Niven E, Maguire C, Gammer TL, Mackey JR, Fulton D, et al: Metabolic modulation of glioblastoma with dichloroacetate. Sci Transl Med 2: 31ra34, 2010.

86. Pastò A, Bellio C, Pilotto G, Ciminale V, Silic-Benussi M, Guzzo G, Rasola A, Frasson C, Nardo G, Zulato E, et al: Cancer stem cells from epithelial ovarian cancer patients privilege oxidative phosphorylation, and resist glucose deprivation. Oncotarget 5: 4305-4319, 2014

87. Sun T, Ming L, Yan Y, Zhang Y and Xue H: Beclin 1 acetylation impairs the anticancer effect of aspirin in colorectal cancer cells. Oncotarget 8: 74781-74790, 2017.

88. Morselli E, Galluzzi L, Kepp O, Vicencio JM, Criollo A, Maiuri MC and Kroemer G: Anti- and pro-tumor functions of autophagy. Biochim Biophys Acta 1793: 1524-1532, 2009.

89. Phi LT, Sari IN, Yang YG, Lee SH, Jun N, Kim KS, Lee YK and Kwon HY: Cancer stem cells (CSCs) in drug resistance and their therapeutic implications in cancer treatment. Stem Cells Int 2018: 5416923, 2018 